\title{
Neurochemical Sensitization in the Pathophysiology of Schizophrenia: Deficits and Dysfunction in Neuronal Regulation and Plasticity
}

\author{
Jeffrey A. Lieberman, M.D., Brian B. Sheitman, M.D., and Bruce J. Kinon, M.D.
}

Existing pathophysiological models of schizophrenia are limited in their ability to account for all the clinical dimensions of the disorder. The purpose of this article is to describe a comprehensive hypothesis of the pathophysiology of schizophrenia and specifically how a deficit in neural regulation of developmental origin can lead to a pathologic form of neuroplasticity, i.e., neurochemical sensitization, which causes the onset and psychotic symptoms of the illness. We propose that the symptoms of schizophrenia may be caused by deficits in neural regulation resulting in a pathologic condition of neurochemical sensitization analogous to the preclinical model of pharmacologicallyinduced behavioral sensitization. This condition, if sustained, can lead to potential neurotoxic effects which produce structural neuronal alterations and persistent morbidity. Several lines of indirect and direct clinical evidence are consistent with this hypothesis. These include the ability of stimulant and psychotomimetic drugs to induce psychosis in normal subjects, the development of apparent sensitization to psychosis-inducing effects of stimulants in chronic stimulant abusers and the increased susceptibility of patients with schizophrenia to the psychotogenic effects of Dopamine (DA) agonists. This hypothesis integrates and extends the work of other investigators and is consistent with specific aspects of the longitudinal course of schizophrenia. The association of longer duration and more episodes of psychosis, with poor treatment response and outcome, are also consistent with this model. From this hypothesis, specific predictions about the illness course, treatment interventions, and pathophysiologic features of schizophrenia can be derived and tested through clinical investigation.

[Neuropsychopharmacology 17:205-229, 1997]

(C) 1997 American College of Neuropsychopharmacology.

Published by Elsevier Science Inc.
KEY WORDS: Schizophrenia; Dopamine; Behavioral sensitization; Pathophysiology; Neuroplasticity

Despite the burgeoning knowledge in the neurosciences and the increasing efficacy of treatments for the psycho-

From the Department of Psychiatry and Mental Health Clinical Research Center, University of North Carolina School of Medicine, Chapel Hill, North Carolina.

Address correspondence to: Jeffrey A. Lieberman, M.D., Department of Psychiatry, University of North Carolina School of Medicine, Chapel Hill, NC 27514-7160.

Received August 8, 1996; revised January 28, 1997; accepted March 5, 1997. pathology of schizophrenia, investigators have been unable to elucidate the pathophysiology and etiology of schizophrenia. The heterogeneity of the disorder, manifest in its highly variable phenomenology, treatment response, illness course, and outcome, is frequently cited as the potential reason for these difficulties (Andreasen and Carpenter 1993). There have been numerous attempts to identify homogeneous subtypes of schizophrenia, but none have been definitively validated.

It has been postulated that the heterogeneity in patients with schizophrenia may be due to multiple etiologies resulting in different pathophysiologic mechanisms 
(Tsuang et al. 1990), or alternatively, as the result of a common etiopathogenic process (Crow 1990a) with innate constitutional differences between people (Carpenter and Kirkpatrick 1988) and its potential for expression at different stages of maturational development (Weinberger et al. 1987), or environmental factors (Murray et al. 1986; Lieberman et al. 1990; McCreadie et al. 1993) that may be responsible for some of the variability in disease manifestations and course.

At the same time, a debate has evolved as to whether the disease process in schizophrenia is wholly of neurodevelopmental pathology or also involves a pathophysiological component (possibly neurodegenerative) that progresses in the course of the illness (Carpenter et al. 1991; 1993; Waddington In Press). Various investigators influenced by the clinical deterioration evident in the longitudinal course of schizophrenia, originally emphasized by Kraepelin $(1919,1971)$, have posited the involvement of neurodegenerative processes (Olney 1989, 1995; Lieberman et al. 1990; Wyatt 1991, 1995; Loebel et al. 1992; Coyle 1995). On the other hand, Weinberger (1987, 1995), among others (Feinberg 1982; Crow 1990a; Murray et al. 1992; Murray 1994; Bloom 1993), has persuasively argued that neurodevelopmental pathology, long preceding the formal onset of the disorder, eventually leads to a static encephalopathy.

Investigators have previously suggested the potential involvement of mechanisms of neuronal plasticity in a variety of normal developmental processes, e.g., learning and memory (Hebb 1949; Kandel and Schwartz 1982; Teyler and DiScenna 1987; Cotman et al. 1988; Robertson 1992), as well as pathologic conditions including: schizophrenia (Braff et al. 1978; Feinberg 1982; Zigmond et al. 1990; Grace 1991; Glenthoj et al. 1993b); psychosis (Post and Kopanda 1976; Kalivas and Stewart 1991); affective disorders (Post et al. 1986, 1992a, 1992b); epilepsy (Goddard 1967; Post et al. 1976); substance abuse (Post et al. 1976; Nestler 1993; Grace 1995); posttraumatic stress disorder (Post et al. 1988; Charney et al. 1993; Friedman 1994); and tardive dyskinesia (Draganow et al. 1990). The purpose of this article is to describe a comprehensive hypothesis of the pathophysiology of schizophrenia and specifically how a deficit in neural regulation can lead to a pathologic form of neuroplasticity, i.e., neurochemical sensitization, which causes the onset and psychotic symptoms of the illness. This hypothesis integrates and extends the work of other investigators (Crow 1980; Post et al. 1976, 1986; Post 1980, Weinberger 1987, 1995; Csernansky et al. 1990; Kalivas and Stewart 1991; Grace 1991, 1993, 1995), and we believe provides greater explanatory power for the clinical phenomena of the disease.

We will briefly review selected pathophysiologic models of schizophrenia and their limitations (to provide a context in which to present our hypothesis), propose our pathophysiologic model of schizophrenia, describe animal models depicting the behavioral and neurobiological manifestations of sensitization, examine the clinical and neurobiological data that support sensitization in schizophrenia, describe the clinical phenomena and neurobiology of syndromes related to schizophrenia which also adhere to a sensitization model or to analogous plasticity models, and lastly describe the implications of this hypothesis and experiments by which to test it.

\section{SELECTED NEURODEVELOPMENTAL AND NEUROCHEMICAL HYPOTHESES OF SCHIZOPHRENIA}

Prevailing etiopathophysiologic hypotheses of schizophrenia postulate neurodevelopmental models of disease pathogenesis. These state that specific pathogenic lesion(s) or process(es) (genetic or environmental), precede the formal onset of the disorder occurring in gestation or early postnatal periods. There is strong evidence of a genetic component in the etiology of schizophrenia from family, twin, and adoption studies (Tsuang et al. 1991; Kendler and Diehl 1993). However, since there is only a $30-50 \%$ concordance rate for schizophrenia among monozygotic twins (Kendler and Diehl 1993), it is believed that there must be some epigenetic or environmental factor(s) that influences the expression of genes. Other etiologic factors that, individually or in combination with genetic vulnerability (the so-called two hit model), can lead to schizophrenia have included prenatal viral exposure or autoimmune reactions (Torrey 1991; Murray et al. 1992; Kirch 1993), or nutritional deficiency (Susser and Lin 1991) and obstetric complications (Lewis and Murray 1987).

\section{Neurodevelopmental Hypotheses}

The evidence in support of neurodevelopmental hypotheses includes: consistent findings of abnormalities in cytoarchitecture and synaptogenesis in brain regions which undergo maturation during gestation and persist into adulthood and, presumably, are present at the onset of schizophrenia (Kovelman and Sheibel 1984; Jacob and Beckmann 1986; Akbarian et al. 1993a, 1993b, 1995; Benes 1995a); the appearance of prenatally determined minor physical anomalies (Green et al. 1994), including dermatoglyphic differences between monozygotic twins discordant for schizophrenia (Bracha et al. 1991); the premorbid history of many schizophrenic patients who had social, motor, and cognitive deficits (Fish 1977; Erlenmeyer-Kimling and Cornblatt 1987; Walker and Lewine 1990; Done et al. 1994); the lack of any definitive evidence of neurodegeneration, e.g., gliosis (Bogerts 1993); and the existence of brain pathomorphology prior to, and at the onset of, illness with lack of defini- 
tive evidence of its progression (Weinberger 1984; Illowsky et al. 1988; Lieberman et al. 1992).

Three neurodevelopmental theories attempt to explain the substantially delayed onset of the symptoms of schizophrenia from the time of the initial pathogenic process. These include: 1) the failure in the cortical neuronal pruning process in adolescence and early adulthood which coincides with the characteristic peak period of onset of schizophrenia (Feinberg 1982); 2) a failure in the development of lateralization of function and cerebral asymmetry which leads to psychotic symptom development in the context of neurodevelopmental maturation (Crow 1990a); and 3) the maturation of the dorsolateral prefrontal cortex in early adulthood which results in the bringing "on line" of a dormant lesion in the limbic system (Weinberger 1987) and subsequent mesiotemporal frontal disconnectivity (Lipska et al. 1995). This latter explanation of the pathophysiology of schizophrenia is supported by an animal model in which a neonatally induced lesion in the ventral hippocampus of rodents does not manifest itself behaviorally until post puberty (Lipska and Weinberger 1993a).

\section{Dopamine Hypothesis}

While aberrant neurodevelopmental processes (engendered by genetic or environmental etiologic factors) predispose patients to the disease, the actual onset and course of the illness have been explained, predominantly, by neurochemical and stress/vulnerability hypotheses. The dopamine (DA) hypothesis, despite its obvious limitations, remains the preeminent neurochemical theory of schizophrenia (Snyder et al. 1974; Meltzer and Stahl 1976; Davis et al. 1991). It postulates that an overactivity in neurotransmission from DA cell bodies located in the ventral tegmental area (VTA) of the midbrain, to their terminal fields in the nucleus accumbens and limbic cortex, results in the development of psychotic symptoms. Two lines of evidence support this, both indirect, yet formidable. The first is that the therapeutic dose of antipsychotic drugs is proportional to their binding affinity for the D-2 receptor (Creese et al. 1976; Seeman et al. 1976). The second is from studies of psychostimulants which show that a significant number of schizophrenia patients will have an exacerbation of their psychotic symptoms if challenged with a low dose of a DA agonist that would not produce these symptoms in "normal" subjects (Lieberman et al. 1987). In addition, high enough doses of DA agonists can produce psychotic symptoms in subjects with no prior history of psychosis (Angrist and Gershon 1970), which can be reversed by antipsychotic drugs (Angrist et al. 1974).

The DA hypothesis of schizophrenia has undergone multiple revisions and has been extended to include both cortical and subcortical components (Weinberger 1987; Seeman 1987; Davis et al. 1991; Grace 1991;
Deutch 1992). Deafferentation of frontal cortical neurons has been shown to result in decreased cortical DA activity and increased subcortical DA activity (Pycock et al. 1980). The hypodopaminergic state in the frontal cortical terminal fields of the (mesocortical) DA neurons, whose cell bodies are located in the VTA, has been hypothesized to be the basis of the "negative symptoms" of schizophrenia, i.e., avolition, apathy, alogia, and asociality, while hyperactivity of mesolimbic DA neurons are believed to cause the psychotic ("positive symptoms") of the disorder (Weinberger 1987; Weinberger et al. 1988; Davis et al. 1991). Grace (1991) has suggested a mechanism by which this can occur involving the regulation of DA release in subcortical regions by two independent mechanisms, a transient or impulse dependent "phasic" DA release resulting from VTA neuronal firing and a sustained or "tonic" release regulated by prefrontal cortical afferents. A deficiency in prefrontal cortical activity would result in a decrease of tonic inhibition of phasic DA release from mesolimbic neurons.

\section{Glutamate Hypothesis}

At the same time, there are numerous limitations of the DA hypothesis. First, no direct evidence of pathologic DA neuronal activity, e.g., increased levels of DA, its metabolites, or receptors, that are not potentially artifacts of antipsychotic drug treatment have been consistently found. Second, functional imaging studies have found no differences in the percentage of $\mathrm{D}-2$ receptor occupancy between responders and nonresponders to antipsychotic medication (Wolkin et al. 1989; Coppens et al. 1991; Pilowsky et al. 1993). Third, the atypical antipsychotics clozapine and risperidone have lower D-2 affinities that are disproportionate to the doses at which they produce therapeutic effects (Kerwin 1994; Seeman and Van Tol 1994). Fourth, drugs that alter opiate, serotonin, and excitatory amino acid neurotransmission have the ability to induce psychotic states (Snyder 1987). Fifth, a variety of other neurotransmitter abnormalities, in addition to DA, have been reported in neurochemical studies of schizophrenic patients (reviewed in Lieberman and Koreen 1993). Alternative neurochemical hypotheses of schizophrenia have also been postulated (reviewed in Lieberman and Koreen 1993). More recent ones have emphasized the primacy of the role of glutamatergic neurons (Javitt and Zukin 1991) and their interaction with DA via GABAergic interneurons in a corticostriatal-thalamocortical feedback loop (Carlsson and Carlsson 1990). These suggest that deficiencies in the inhibitory effects of cortical subcortical glutamatergic projections result in enhanced DA neuronal activity producing pathologic behavior. Most recently evidence of NMDA receptor hypofunction (O1ney and Farber 1995) or antagonism (Tsai et al. 1995) 
that could result in DA hyperactivity has been derived from rodent and human post-mortem studies.

\section{Stress and Vulnerability Hypothesis}

It has long been known that schizophrenia is a stress sensitive disease. The onset of illness is frequently precipitated by a stressful event, while relapses are often occasioned by stressors (Norman and Malla 1993). This has given rise to the notion that schizophrenia develops when a threshold of stress tolerance in a vulnerable individual is exceeded (Zubin and Spring 1977). Thus, although all people are vulnerable to stress, patients predisposed to or with schizophrenia are more sensitive and react uniquely to stressful stimulation. A substantial number of studies have demonstrated the role of DA neuronal activity specifically of the mesolimbic and mesocortical systems in mediating the behavioral effects of stress stimulation (Deutch and Roth 1990; Kalivas and Stewart 1991).

\section{PATHOPHYSIOLOGY AND THE LONGITUDINAL COURSE OF SCHIZOPHRENIA}

Despite their intellectual appeal and evidentiary support, a major limitation of existing pathophysiological theories in their inability to account for the phenomenology and course of schizophrenia. Particular aspects of the illness which have not been adequately explained by existing models are its characteristic onset in late adolescence and early adulthood, the longitudinal course and process of deterioration (in terms of exacerbations and remissions and the accrual of morbidity in the form of positive, negative and cognitive symptoms and functional impairment). In light of the neurodevelopmental and genetic/epigenetic theories of schizophrenia, which postulate that the pathogenic process and consequent neuropathology occur in gestation or early development, perhaps the most difficult feature of the illness to explain is the delay in the onset of illness until the second or third decades of life. Moreover, no pathophysiological model has satisfactorily explained the longitudinal course of the illness and its variable expression through all of its phases, though several have accounted for some phases and dimensions of the illness (Crow 1980, 1985; Feinberg 1982; Hafner et al. 1993; Weinberger 1987; Carpenter and Kirkpatrick 1988; Lipska and Weinberger 1993; Andreasen et al. 1995). For example, what determines the age and mode of onset of illness? Why do some patients become treatment resistant? What accounts for the development of negative symptoms and the evolution of psychopathology? And fi- nally, what factors determine illness course, outcome and clinical deterioration?

Thus, there is a need to develop new or broaden existing pathophysiologic models of schizophrenia. In this context we have hypothesized that disturbances in the normative processes of neuronal plasticity which facilitate cellular adaptation to physiologic stimulation, may be a critical factor in the pathophysiology of schizophrenia. Previous investigators have suggested that one such neuroplastic mechanism, which plays an important role in disease pathophysiology is sensitization (Post and Kopanda 1976; Csernansky et al. 1990; Kalivas and Stewart 1991; Grace 1991; Lieberman et al. 1990, 1994b; Glenthoj et al. 1993b). Behavioral sensitization is a well defined and widely replicated phenomenon in which intermittent pharmacologic (or environmental) stimulation produces a progressive and enduring enhancement of a behavioral response rather than decreased response (tolerance) (Wolf et al. 1993). We support the proposal of prior investigators that sensitization does indeed play a critical role in the disease process, (in our view particularly in the prodromal and early phases of the illness). However, we would extend the previous hypotheses by suggesting that sensitization does not represent the entire pathophysiologic process in schizophrenia but rather is one stage of a sequence of pathophysiogical events which occurs at the critical stage of disease onset and early course. In fact, it is our extended hypothesis for a comprehensive model of schizophrenia that the pathophysiology of schizophrenia unfolds in three stages. These are described in Table 1. The first arises in the gestational and perinatal periods and consists of neurodevelopmental cytoarchitectural abnormalities in the cerebral cortex that result from a failure of normal neural development and migration which establishes a deficient matrix for the ensuing neuromaturational events that enables synaptic connectivity. These failures ultimately lead to a deficient capacity for neuromodulation. The second stage arises much later (in adolescence and early adulthood) and underlies the prodromal, psychosis onset and early course of the illness. This involves the development of endogenous neurochemical sensitization in response to environmental stimulation (e.g., life events, stress, drug abuse). The third stage involves the development of a limited neurotoxicity which occurs as consequence of progressive sensitization and underlies the deterioration and residual phases of the illness. The evidence for the first stage has been extensively reviewed (Mednick and Hollister 1995; Murray 1994; Bloom 1993). The evidence for the third stage is the most speculative and only beginning to emerge. Consequently, although we will briefly describe the comprehensive model later in the article in order to put the sensitization process in context, we will focus on the second stage, for which we believe there is substantial evidence. 
Table 1. Pathophysiological Stages of Schizophrenia

\begin{tabular}{|c|c|c|c|}
\hline Stage & $\begin{array}{c}1 \\
\text { Neurodevelopmental }\end{array}$ & $\stackrel{2}{2}$ & $\begin{array}{c}3 \\
\text { Neurotoxic }\end{array}$ \\
\hline Period of life cycle & Gestation, perinatal & $\begin{array}{l}\text { Late adolescence, } \\
\text { early adult }\end{array}$ & Adult \\
\hline Phase of illness & $\begin{array}{l}\text { Premorbid } \\
\text { (subclinical) }\end{array}$ & $\begin{array}{l}\text { Prodromal, onset, } \\
\text { deteriorative }\end{array}$ & Residual \\
\hline $\begin{array}{l}\text { Pathophysiological } \\
\text { process }\end{array}$ & $\begin{array}{l}\text { Unknown, (possibly } \\
\text { genetic, infectious } \\
\text { immune, traumatic) }\end{array}$ & $\begin{array}{c}\text { Neurochemical } \\
\text { sensitization }\end{array}$ & $\begin{array}{l}\text { Neurotoxicity } \\
\text { (unknown mechanism, } \\
\text { possibly oxidative } \\
\text { stress, excitotoxic } \\
\text { apoptosis) }\end{array}$ \\
\hline Anatomic loci & Cortical neurons & $\begin{array}{l}\text { Meso-limbic- } \\
\text { striatal cortical } \\
\text { circuits }\end{array}$ & $\begin{array}{l}\text { Cortical-limbic } \\
\text { striatal neurons }\end{array}$ \\
\hline
\end{tabular}

Table 1 depicts three hypothesized pathophysiological stages of schizophrenia. Each stage is described in terms of when it arises (period of life cycle), which aspects and clinical phases of the illness it underlies (phase of illness), its pathophysiology (pathophysiological process), and its anatomic and neural substrate (anatomic loci). The first stage arises in the gestational and perinatal periods, and consists of cytoarchitectural abnormalities in the cerebral cortex that result from a failure of normal neural development and synaptogenesis which establishes a deficient matrix for the ensuing neuromaturational events. This failure ultimately leads to a deficient capacity for neuromodulation. The second stage arises much later (in adolescence and early adulthood) and underlies the prodromal, psychosis onset, and early course of the illness. This involves the development of neurochemical sensitization in response to environmental stimulation (e.g., life events, stress, drug abuse). The third stage involves the development of a limited neurotoxicity which occurs as consequence of progressive sensitization and underlies the deterioration and residual phases of the illness.

\section{SENSITIZATION}

\section{Models of Sensitization}

Sensitization is defined as an augmented motor or behavioral response resulting from prior exposure to noxious stimuli (Kandel 1991). Sensitization in the invertebrate model has a short-term form lasting minutes and a long-term form which may last weeks or longer depending on the number of stimuli presented. Shortterm sensitization has been studied at the cellular level in the aplysia and found to be due to synaptic facilitation (Kandel and Schwartz 1982). There is evidence of a continuum from short-term to long-term sensitization in the aplysia which includes the following: the same locus for synaptic connections; enhanced neurotransmitter release; and the same neurotransmitter and second messengers implicated (Greenberg et al. 1987). However, there are also important differences (Goelet et al. 1986). Long-term sensitization requires the synthesis of new protein and mRNA which is not necessary for the short-term phenomena (Alberini et al. 1994). This has two important consequences in the aplysia. First, there is a persistent activation of the cAMP-dependent protein kinase which allows substrate proteins to be maintained in the phosphorylated state for the longterm (Sweatt and Kandel 1989). Secondly, morphological changes are evident in long-term sensitization with the growth of synaptic connections, with both increased synaptic input and an increase in dendrite size on the motor neurons (Bailey and Chen 1983).
Sensitization has been repeatedly demonstrated in mammalian animal models, mostly with rodents and is often referred to as behavioral sensitization. This has typically taken the form of an augmentation in locomotor activity in response to a pharmacologic or stressful stimulation, due to prior pharmacologic pretreatment. This is assessed by either an increased number of cage crossings or an increase in the magnitude or intensity of repetitive behaviors (stereotypies). However, the neurobiology of mammalian sensitization at the cellular level, either short- or long-term, has not been fully elucidated. Nevertheless, a great deal has been learned about both the inductive and expressive components of behavioral sensitization (reviewed by Robinson and Becker 1986; Kalivas and Stewart 1991). Behavioral sensitization in rodents can be induced by a variety of pharmacologic agents, including DA and opiate agonists (Robinson and Becker 1986), and noncompetitive NMDA antagonists (Wolf and Khansa 1991). Environmental stress (Sorg and Kalivas 1991) can also induce sensitization and has been demonstrated to be crossreactive with many types of pharmacologically induced sensitization, including DA and opiate agonists (Antelman et al. 1980; Kalivas and Stewart 1991). In addition, a conditioning component has been demonstrated in previously sensitized animals whereby animals exhibit stereotyped behavior, even before receiving additional injections, if placed in the same observation cages (Ellinwood 1971). Behavioral sensitization in mammals, as in lower order organisms, can be induced by a single 
stimulus, with the magnitude of the response dependent on both the number of times that the stimulus is repeated, and the length of time from the pretreatment to the challenge, with the longer time interval producing more augmentation (Antelman et al. 1986). However, the temporal boundaries of this phenomenon in terms of the production of a maximum or loss of effect have yet to be determined. Furthermore, the pattern of administration, i.e., intermittent versus continuous, is a more critical variable than the total amount of pharmacologic stimulation (Post 1980; Reith et al. 1987; King et al. 1992; Csernansky et al. 1990; Glenthoj et al. 1990.)

\section{Induction of Sensitization}

Sensitization has two phases, induction and expression. Available data suggest that the induction of sensitization requires stimulation of the DA cell bodies in the ventral tegmental area (VTA) (Kalivas 1993a,c). Injection of amphetamine or morphine directly into the VTA, or systemically, induces sensitization to a future amphetamine challenge (Kalivas and Stewart 1991). The injection of DA or opiate agonists directly into the DA terminal fields, both the striatum (Kalivas and Stewart 1991) or frontal cortex (Hooks et al. 1992) does not induce sensitization. This effect appears to be mediated through D-1 receptors since an injection of the selective D-1 antagonist SCH-23390 into the VTA concurrently with amphetamine (Stewart and Vezina 1989) or morphine (Kalivas and Stewart 1991) blocks the induction of sensitization. Injection of selective D-2 antagonists (e.g., sulpiride) concurrently with a nonselective DA agonist does not block the induction of sensitization (Vezina and Stewart 1989). The preferential D-2 antagonists haloperidol and pimozide, that have a lower affinity for the D-1 receptor, block the development of behavioral sensitization from cocaine, amphetamine, and morphine administration respectively (Weiss et al. 1989; Ujike et al. 1989; Vezina and Stewart 1989). Morphine induced behavioral sensitization, that can also be blocked by coadministration of naloxone (Kalivas and Stewart 1991), has been hypothesized to occur via its inhibitory actions on inhibitory GABAergic interneurons resulting in enhanced somatodendritic DA release (Hommer and Pert 1983; Kalivas and Stewart 1991; Lacey et al. 1989). The indirect role of GABAergic neurotransmission is also supported by the ability of the $\mathrm{GABA}_{\mathrm{B}}$ agonist baclofen, when injected into the VTA, to block the induction of behavioral sensitization from systemic cocaine administration (Kalivas and Stewart 1991).

The excitatory amino acids (EAA) may have a central role in the induction process. Systemic administration of MK-801, an NMDA antagonist, can block the induction of sensitization from systemically administered cocaine (Wolf and Khansa 1991) or morphine (Jeziorski et al. 1994). Systemic administration of DNQX, a non-
NMDA competitive antagonist, will block the induction and expression of sensitization from systemically administered amphetamine (Karler et al. 1991). Though the effects of EAA stimulation have been postulated to occur via indirect effects on DA neurotransmission, repeated administration of MK-801 alone resulted in sensitization to its own locomotor stimulant effects, but not to a subsequent amphetamine challenge (Wolf and Khansa, 1991).

In addition to the VTA, two temporal lobe structures, the amygdala and hippocampus, may be anatomical loci where EAA receptor stimulation is required for the induction process to occur. Pretreatment with the NMDA antagonist MK-801 administered directly into the ventral amygdala or the VTA, blocked the induction of behavioral sensitization resulting from systemic cocaine administration (Kalivas 1993b). Lesioning of the fimbria fornix which interrupts the hippocampal efferent glutamatergic fibers to the nucleus accumbens also prevented the induction of behavioral sensitization from methamphetamine administration (Yoshikawa et al. 1991).

Based on the anatomical and neurochemical findings, the induction of sensitization appears to require D-1 receptor stimulation in the VTA either directly by DA agonists, or indirectly via GABAergic inhibition, or, alternatively, via EAA receptor stimulation alone.

\section{Expression of Sensitization}

In contrast to its induction, the expression of sensitization is contingent upon stimulation of the DA terminal fields (Kalivas 1993d). Administration of DA agonists, either systemically or directly to the striatum (but not the VTA) in previously sensitized animals, results in an enhanced behavioral response. This effect appears to be D-2 mediated since challenging previously sensitized animals with selective D-2, but not D-1 agonists, results in an augmented behavioral response (Levy et al. 1988; Ujike et al. 1990). In addition, while NMDA antagonists administered systemically are able to block the induction of sensitization, they have no effect on the expression of an augmented behavioral response in previously sensitized animals (Karler et al. 1991). However, D-2 antagonists cannot fully block the enhanced response in previously sensitized animals (Martin-Iverson and Reimer 1994). Based on these results it has been hypothesized that the induction and expression of sensitization are mediated by separate neurobiologic processes (Karler et al. 1991; Kalivas and Stewart 1991).

\section{Neurobiologic Basis of Sensitization}

Investigations in mammalian species, primarily rodents, to delineate the neurobiology of sensitization have concentrated on three brain regions: 1) the DA terminal fields in the dorsal and ventral striatum; 2) the frontal 
cortex; and 3) the midbrain DA cell bodies. Contrary to expectations, an upregulation of DA neurotransmission, analogous to that seen in the invertebrate model, has not been found. Studies of postsynaptic dorsal striatal DA receptor binding have been inconclusive with more evidence indicating a downregulation than an upregulation, and a similarly inconclusive but a predominant pattern of downregulated D-2 receptors also evident in the ventral striatum (Robinson and Becker 1986). This apparent downregulation of D-2 binding in sensitized animals suggests the potential presence of increased synaptic neurotransmitter concentrations. Studies of freely moving animals pretreated with DA agonists that measured extracellular DA concentrations in the striatum through in vivo microdialysis, both before and after a DA agonist challenge, generally agree that prior to the challenge extracellular DA concentrations are not elevated (Kalivas and Stewart 1991). However, post challenge extracellular DA concentrations were found to be elevated in most (Kalivas and Stewart 1991) but not all studies (Hurd et al. 1989; Segal and Kuczenski 1992). The discrepancy in results may be secondary to the time interval from the pre- to postchallenge as well as other methodologic differences. Consistent elevations in postchallenge extracellular DA are found in those studies that used at least a 2 week interval from pre- to postchallenge. The association of dysregulation in extracellular DA with disturbed behavior suggests that the abnormal substrate may not be the absolute concentration. Supportive of this interpretation is a recent study (Giros et al. 1996) of mice with the gene for their DA transporter (DAT) "knocked out" which resulted in behaviors that resembled those of a sensitized animal. As the DAT knock-out mice had decreased synaptic levels of DA as measured by in vivo microdialysis (under basal and poststimulation conditions), it was concluded that the critical factor responsible for the abnormal behavior was not the absolute level but the disturbance in synaptic regulation that resulted in a longer period of DA in the synapse at physiologic concentrations. Preliminary results of PET studies in humans (that will be subsequently described) have also shown disturbances in synaptic regulation of DA predominantly in the form of increased concentrations of extracellular DA (Reith et al. 1994; Breier et al. 1995; Laruelle et al. 1996; Farde et al. 1996).

There is also evidence that subsequent to sensitization by amphetamine (Robinson et al. 1985; Hammura and Fibiger 1993), or by an NMDA antagonist (Wedzony et al. 1993), acute administration of a DA agonist produces increased extracellular DA concentrations in the frontal cortex, while basal levels are unchanged.

\section{Developmental Course of Sensitization}

Behavioral sensitization is dependent upon the stage of maturational development. It cannot be induced prior to postnatal day 21 in the rat by intraperitoneal drug administration of amphetamine (Fujiwara et al. 1987; Kolta et al. 1990; Tsuchida et al. 1994) or phencyclidine (Scalzo and Holson 1992). Interestingly, this parallels the experience with ketamine use as a dissociative anesthetic in children but not in adults in whom it produces psychotogenic effects (Marshall and Longnecker, 1990). This had been explained as normal ontogenetic development of the DA system by the fact that the DA autoreceptor is neither differentiated nor functional until that time, while the postsynaptic DA receptor had been reported functional by postnatal day 4 (Hedner and Lundborg 1985). Interestingly, stress at critical stages of early development can also lead to altered DA activity and stress reactivity in the adult animal (Takahashi et al. 1992), as can prenatal exposure of rodents to DA agonists (Johns and Noonan 1995). This time course in development of behavioral sensitization demonstrates the time and maturation dependent nature of the expression of this pathologic phenomenon. A similar sequence of events may be seen in the natural course of schizophrenia, whereby the neuropathologic changes appear to predate the onset of psychosis, though most patients do not have their formal onset of illness until late adolescence or early adulthood.

\section{GENERIC FEATURES AND FUNCTION OF NEUROPLASTIC MECHANISMS}

In addition to sensitization, mechanisms of neuronal plasticity are involved in a wide array of central nervous system functions, and are broadly defined as the ability of neurons to alter some functional property in response to alterations of input, by changing the effectiveness of synaptic connections (Shaw et al. 1994). Neuroplastic mechanisms can be involved in normative, adaptive, and pathologic functions, and include long term potentiation (LTP), kindling and habituation. These are clearly different phenomena, yet appear to respond in an analogous fashion to different patterns of stimulation (Dragunow et al. 1989; Kandel 1991; Shaw et al. 1994). Long-term potentiation has been hypothesized as a neurobiologic mechanism in learning and behavior (Teyler and DiScenna 1987; Cotman 1988; Kandel 1991), while kindling has been hypothesized as a pathophysiologic mechanism in the major affective disorders (Post et al. 1986) and temporal lobe epilepsy (Sutula 1990). Habituation, defined as a learned suppression of a response to a stimulus which is neither noxious nor rewarding, is an adaptive response in the invertebrate and results from diminished neurotransmission between sensory, motor, and interneurons (Kandel 1991).

Major questions remain unanswered in the physiology of neuronal plasticity. Initial attempts to identify a "crucial molecule" common to all forms of central nervous system plasticity has now been replaced by a hy- 
pothesis of a dynamic cascade of interacting molecules which may differ from one system to the next, but with the underlying nature of the neuronal modification being similar across systems (Shaw et al. 1994). It has been hypothesized that the function of neuronal plasticity in adult animals is to provide a means to respond to perturbations of the central nervous system that will allow the maintenance of the baseline homeostasis. Moreover, neuroplastic responses are not limited to the system directly perturbed but can propagate changes to other neurotransmitter systems with which they functionally interact.

Though sensitization as it occurs in the invertebrate, e.g., aplysia, and the mammal, results in an enhanced locomotor response, it is unlikely that identical neurobiologic mechanisms mediate the behavioral augmentation in both species. In addition, the phenomenon as described in the invertebrate model is adaptive for the organism, while the sensitization described in mammals appears to reflect a pathologic process. Whether the augmented behavioral response of mammals resulting from prior stimulation is the result of enhanced or diminished synaptic neurotransmission (e.g., the result of a diminished inhibitory input which allows the expression of a previously suppressed behavior) is unknown. Disinhibition of behavior normally regulated by higher cortical functions is a long established principle and is consistent with the expression of striatal functions and has been hypothesized as a general mechanism underlying many of the symptoms observed in movement disorders, e.g., chorea, myoclonus, tics, tremors, and ballistic movements, as well as behavior (Jackson 1931; Chevalier and Deniau 1990).

\section{Adaptive and Pathological Forms of Neuronal Plasticity}

Different forms of neuronal plasticity can produce adaptive and pathologic effects. Long-term potentiation reflects a neurophysiologic capacity of neurons whereby an enduring enhancement of the post synaptic response, measured by an increase in the excitatory synaptic potential, results from prior afferent stimulation (Teyler and DiScenna 1987; Cotman et al. 1988). This process is central to learning and memory, and has been studied most extensively in the hippocampus where activation of NMDA receptors is necessary to induce LTP (Shaw et al. 1994). The NMDA receptor has also been hypothesized to be central to the kindling phenomenon (McNamara et al. 1990). Kindling is a pathophysiologic process whereby repetitive subthreshold electrical or chemical stimuli to certain brain areas will eventually induce threshold responses (Goddard 1967; Neppe 1985).

The similarities and differences between LTP and kindling have been extensively reviewed (Cain 1989; Draganow et al. 1989). Although the premise that LTP may be the cellular mechanism of kindling has face validity (since both are induced by the localized application of brief, high frequency trains of electrical impulses and result in a pattern of progressively augmented responses), this has not been fully determined. Indeed there are also significant differences between LTP and kindling. Among these are that LTP is adaptive or physiologic, while kindling leads to a pathologic process; LTP decays in a few hours to a few weeks whereas kindling is enduring; if LTP is allowed to decay to baseline, no evidence of an enhanced responsiveness is evident if LTP is reintroduced; enhanced norepinephrine transmission will consistently retard kindling while it either has no effect or will enhance LTP; $c F O S$ induction occurs in kindling but is seen only in certain types of LTP; although some mutual facilitation often exists between kindling and LTP, a variety of interactions have been reported including no enhancement and sometimes a diminished response. Thus, neurophysiologic phenomena that appear to be generally analogous can differ in their functional properties as well as whether their ultimate effects are adaptive or pathologic.

It has also been hypothesized that kindling and the behavioral sensitization of mammals may be representative of the same or analogous phenomena, one being induced by intermittent electrophysiologic stimulation, the other by intermittent pharmacologic stimulation (Post and Kopanda, 1976). This is supported by studies demonstrating the enduring nature of both phenomena (Goddard et al. 1969; Robinson and Becker 1986), their mutual facilitation (Kirby and Kokkinidis 1987; Csernansky et al. 1988; Glenthoj et al. 1993a; Schenk and Snow 1994), the expression of immediate early gene products in both (Norman et al. 1993; Kiessling and Gass 1993); the ability of the NMDA antagonist MK-801 to block the induction of sensitization (Wolf and Khansa 1991; Kalivas 1993) and inhibit the kindling process (Sato et al. 1988), and the fact that kindling and behavioral sensitization both result in pathologic neuronal activity. We can speculate that both kindled seizures and the development of behavioral sensitization from intermittent DA agonist administration (whose behavioral analogue in humans we suggest would be psychopathology including psychosis) may result from a progressively diminishing capacity of regulatory or homeostatic mechanisms to maintain the baseline nonpathologic level of VTA DA neuronal activity. Therefore, the pattern of stimulation (Csernansky et al. 1990; Glenthoj et al. 1990) and the anatomic location of neurons stimulated may be the critical variables in determining the specific nature of pathologic responses. The pattern and frequency of CNS perturbation, intermittent vs. continuous, determine the magnitude of response, whereas the anatomic site and neuronal population perturbed results in the specific type of the response. In rodents, stimulation of the dorsal striatum 
produces stereotypies (Randrup and Munkvad 1965; Costall and Naylor 1977): the ventral striatum-hyperactivity (Seeger et al. 1982), hippocampus-seizures (Sutula 1990), and amygdala-enhanced startle response (Rosen and Davis 1988).

\section{CLINICAL EVIDENCE FOR NEUROCHEMICAL SENSITIZATION IN SCHIZOPHRENIA}

\section{Stimulants Effects in Normals, Substance Abusers and Schizophrenics}

Three lines of evidence suggest the potential role of neurochemical sensitization as a pathophysiologic mechanism in schizophrenia. First, DA agonism in the form of high dose administration of psychostimulants ("stimulant loading") can produce psychotic symptoms including delusions, hallucinations, and a thought disorder which mimic schizophrenia in healthy subjects (Griffith et al. 1968; Angrist and Gershon 1970). If stimulant administration is stopped, the psychotic symptoms will spontaneously subside, or can be reversed by the administration of antipsychotic medication (Angrist et al. 1974). Second, single administrations of stimulants at low doses (which do not produce psychotic symptoms in healthy subjects) have been shown to exacerbate psychotic symptoms in a substantial proportion of patients with schizophrenia (Janowsky et al. 1973; Lieberman et al. 1987). This exacerbation spontaneously subsides within hours and can be reversed with antipsychotic medication (Angrist et al. 1974). Moreover, the psychotogenic potency of stimulants is proportional to their potency in displacing DA from presynaptic storage pools, and/or binding to the $\mathrm{DA}$ transporter thereby inhibiting DA reuptake (Janowsky and Davis 1976; Wall et al. 1993; Cline et al. 1992; Volkow et al. 1995). This has been interpreted as evidence that patients with schizophrenia have an enhanced sensitivity to the behavioral effects of DA agonists. The lack of symptom exacerbation in some of the patients has been attributed to the heterogeneity of the illness, or, alternatively, the progression of the illness which results in a diminished responsivity to DA agonist administration (Lieberman et al. 1993a,b). The phenomenon appears to be state dependent in that stable, nonpsychotic schizophrenia patients are less susceptible to develop transient psychosis activation compared to patients with active psychotic symptoms (Lieberman et al. 1987). DA agonist administration has also been examined as a test to predict relapse in schizophrenia (Angrist et al. 1980; Van Kammen et al. 1982; Lieberman et al. 1994a). Stable nonpsychotic patients underwent provocative testing with DA agonists and then were followed prospectively after withdrawal of neuroleptic medications. Patients who had a transient psychotic symptom activation had a significantly shorter time to relapse than patients who did not have a symptom exacerbation. This was interpreted as a possible sign of an increased reactivity of DA neural systems in the patients who became psychotic after DA agonist stimulation (Lieberman et al. 1994).

The third line of evidence comes from observations of stimulant abusers. The intermittent use of stimulants in low to moderate doses, on a chronic basis, has been observed to produce a delayed onset psychosis in a significant proportion of stimulant abusers (Sato et al. 1992). Moreover, after recovery from stimulant induced psychosis, abusers exhibit a lower threshold to the induction of psychotic symptoms upon subsequent stimulant exposure. This phenomenon, referred to as stimulant induced sensitization, has been studied extensively in Japan, where there have been several epidemics of methamphetamine abuse since World War II. As a consequence of repetitive stimulant use a substantial number of persons went on to develop psychotic symptoms which persisted long after the termination of the stimulant intake and ultimately required antipsychotic drug treatment (Iwanami et al. 1994).

Another phenomenon common to both stimulant abusers and schizophrenics is their enhanced vulnerability to stress. It has been widely demonstrated that patients with schizophrenia are susceptible to symptom exacerbation in response to a variety of environmental stressors (Norman and Malla 1993; McCreadie et al. 1993; Mari and Steiner 1994). Moreover, some schizophrenia patients are susceptible to relapse due to psychological stressors, even while maintained on antipsychotic medication (Kane and Lieberman 1987). Stimulant abusers, similarly, have a propensity to experience a psychotic relapse in the context of psychological stress, even during periods of abstinence (Sato et al. 1992).

Though less well studied, the comorbidity of stimulant abuse and schizophrenia has raised concerns about the possibility of their interaction exacerbating the course of schizophrenia and moving it further along a "continuum of severity" leading to a deteriorating course, i.e., resistance to antipsychotic drugs and persistent positive and negative symptoms (Lieberman et al. 1990).

\section{Course of Illness}

Evidence from studies of the longitudinal course of schizophrenia also support a potential role for sensitization in the pathophysiology of the illness. From 30\% to $60 \%$ of patients experience some progression of their illness, with psychotic relapse(s) resulting in lower levels of recovery and higher levels of residual symptoms (Wyatt 1991). The deterioration occurs predominantly in the early stages of the illness (McGlashan and Fenton 1993), the first five years for the most part, while some have even suggested that the prepsychotic phase is the initial period of deterioration (Carpenter and Kirk- 
patrick 1988). Kraepelin's initial descriptions of the deteriorating course of schizophrenia are particularly relevant since they are based on observations prior to the availability of antipsychotic medication. Studies which use typical clinical samples and demonstrate a deteriorating course and outcome for schizophrenia patients are often criticized for possibly reflecting an overrepresentation of more severely ill patients, with the subjects who have a better outcome dropping out of the mental health system, thereby producing a biased population (Regier et al. 1984). Evidence for a deteriorating course, however, has also been found in studies of first episode schizophrenia patients who were then followed prospectively from 1 to 5 years (Huber et al. 1980; May et al. 1981; Crow et al. 1986; Loebel et al. 1992). They found that the length of time a person experienced psychotic symptoms in their first episode of illness, prior to receiving pharmacologic treatment, was a significant predictor of the time to treatment response (Loebel et al. 1992), relapse (Crow et al. 1986), and long-term outcome (Huber et al. 1980; May et al. 1981). Specifically, the longer the duration of psychosis the poorer the treatment response and outcome. In addition, studies that followed patients over successive episodes of illness found that some of the patients took longer to recover or, in some cases, failed to recover as they had in their previous episode (Wyatt 1991; Loebel et al. 1995; Lieberman et al. 1996). It was thus postulated that psychosis may reflect a pathologic process which diminishes the ability of the patient to respond to antipsychotic medication. The pattern of results is consistent with a process of sensitization.

\section{Clinical Neurobiologic Evidence for Sensitization}

Direct evidence of increased DA neuronal activity in schizophrenia has not been consistently demonstrated. Measures which have been studied include DA metabolites (HVA and DOPAC) in CSF, plasma, and urine; anterior pituitary hormones that are regulated by DA (e.g., prolactin and growth hormone) (Lieberman and Koreen 1993), and DA receptors (D-1, D-2, D-4) in postmortem tissue (Seeman et al. 1987; Pearce et al. 1990; Seeman and Van Tol 1995, Murray et al. 1995), and PET scans (Wong et al. 1986; Farde et al. 1990; Sedvall 1992; Nordstrom et al. 1995; Rieth et al. 1994). Studies of DA receptors have produced the most promising results. However, findings of increased numbers of D-2 and D-4 receptors have been clouded by either their failure to be replicated or the possibility of treatment artifact (Tarazi et al. 1994; Nordstrom et al. 1995).

Even if DA receptor numbers were not increased it has been suggested that a receptor based supersensitivity in schizophrenia could result from an uncoupling of D-1 and D-2 receptors (Seeman et al. 1987, 1994; Seeman and Van Tol 1994). In this model the relative proportion of D-2 receptors that exist in a high affinity state (uncoupled to the desensitizing effects of $D-1$. receptors) in the presence of DA is increased in schizophrenia. Thus, a normal number of DA receptors, but with a greater proportion in the high affinity state, could produce an enhanced response to DA stimulation. However, similar studies in sensitized animals have not been conducted.

Interesting results from studies utilizing SPECT and PET scans with the D-2 radioligands, IBZM or C11 raclopride, coupled with a psychostimulant probe to measure, quantitatively, extracellular DA have been described by Logan et al. (1991), Innis et al. (1992), Volkow et al. (1994), Breier et al. (1997), and Laruelle et al. (1996). The paradigm involves obtaining functional imaging scans (SPECT or PET) using a competitive D-2 antagonist as a radioligand before (under unstimulated resting conditions) and following an acute psychostimulant administration (e.g., amphetamine, methylphenidate). The baseline scan provides a measure of D-2 receptor number in the presence of basal concentrations of synaptic DA, while the poststimulant scan provides a measure of extracellular DA that has been released from presynaptic neurons and inhibited from reuptake by inhibition of the DA transporter (simulating phasic release). The difference (decrement) in D-2 binding between the baseline and postdrug stimulation SPECT or PET scans would provide an index of the release of presynaptic and the concentration of synaptic DA. In studies of human and subhuman primates this has been found. Amphetamine or methylphenidate produced an average decrease of $15 \%$ in D-2 binding with IBZM (Innis et al. 1992), and $25 \%-50 \%$ in C- 11 raclopride in healthy volunteers (Volkow et al. 1994). If sensitization occurs in schizophrenia one possible consequence that may be predicted is that these patients would have elevated levels of presynaptic and/or extracellular DA. Preliminary studies (Reith et al. 1994; Breier et al. 1997; Laruelle et al. 1996) are consistent with this hypothesis. They indicate that compared to control subjects patients with schizophrenia have greater decrements in D-2 binding by IBZM (Laruelle et al. 1996) and C-11 raclopride (Breier et al. 1997) as well as increased metabolism of the precursor to DA as measured by F-flouroL-dopa (Reith et al. 1994). However, these studies were of patients who had previously received antipsychotic drug treatment but were presently drug free. Consequently, the possibility that this was a treatment effect cannot be entirely ruled out. Nevertheless, this paradigm offers an exciting new strategy to examine a hypothesized pathophysiological mechanism in psychosis.

Although D-2 receptors have not been found to be downregulated as might be expected with increased synaptic release of DA, this measure is confounded by the upregulating effects of classical antipsychotic drugs. Interestingly, a preliminary study (Farde et al. 1996) 
found decreased D-1 binding in treatment naive schizophrenic patients which is consistent with increased presynaptic release and a sensitization model.

\section{COMPREHENSIVE PATHOPHYSIOLOGICAL MODEL OF SCHIZOPHRENIA}

The human brain may be endowed with a finite capacity for plasticity and neuronal modulation that is inherent in normally functioning neurons, and their networks, and available to compensate for perturbations that disrupt neural homeostasis (Hasselmo 1995). When this capacity is exceeded, untoward responses, including pathologic forms of behavior including psychosis, can be manifest. Examples of this may be seen in descriptions of aberrant behavior in the face of overwhelming stress previously described as "battle fatigue" or "shell shock", and currently as posttraumatic stress disorder (Orner 1992; Gersons and Carlier 1992; Hierholzer et al. 1992), or in the previously described ability to induce psychosis in healthy subjects through psychostimulant loading (Angrist and Gershon 1970) or chronic substance abuse (Iwanami et al. 1994). In these instances previously healthy persons may develop psychopathology in various forms, including psychosis, because their compensatory capacities, psychological and neurobiological, are exceeded. In this context, schizophrenia may be the result of a sequence of events (failures in neural development, migration, and connectivity) that begins with a congenital or early developmental deficiency in the neural substrate that underlies the brain's neuroplastic capacity to respond and compensate for variations in the level and form of neuronal activity. As a result of this deficiency, patients with schizophrenia are more susceptible to the neurophysiological perturbations of environmental experiences that occur in the context of daily life as their compensatory capacity is compromised and more easily exceeded. These if persistent or recurrent can lead to a persistent state of dysregulation and potentially enduring pathologic changes which are at first functional, and ultimately structural.

This longitudinal process is comprised of three related but distinct stages with different temporal, pathophysiological, and clinical characteristics, as described below (see Table 1).

\section{Stage One: Cortical Neuropathology and Deficient Neuromodulatory Capacity}

This first stage is caused by the genetic and/or epigenetic etiologic factors (as previously described) that occur during fetal gestation and early perinatal development, and involves the failure of normal neuronal development and synaptogenesis, and results in a deficiency of the inhibitory capacity of the cortex on subcortical structures. The histopathologic, cytoarchitectural (Kovelman and Sheibel 1984; Jacob and Beckmann 1986; Akbarian et al. 1993a,b, 1995; Bogerts 1993; Benes 1995; Anderson et al. 1996; Daviss and Lewis 1995; Lewis and Anderson 1995; Arnold et al. 1995), and morphometric (Bogerts et al. 1990, 1993; Andreasen et al. 1995; Suddath et al. 1990; Gur et al. 1995) abnormalities described in the cerebral cortex (predominantly in the prefrontal and temporal regions) of schizophrenia patients could reflect the cellular basis for this deficiency or the matrix in which the developmental failure of normal functional processes, (i.e., neuroplasticity, and intracortical and cortical subcortical regulation) could lead to functional pathology. This is also supported by evidence of decreased metabolic rates in the prefrontal cortex in schizophrenia (Weinberger et al. 1988) and chronic cocaine users (Volkow et al. 1994). The prefrontal cortex is believed to regulate subcortical structures (Pycock et al. 1980; Weinberger 1987; Davis et al. 1991; Grace 1991). This neuropathology is clinically manifest as some of the premorbid behavioral precursors to schizophrenia that have been described (Watt 1978; Walker et al. 1991; Fish 1977; Done et al. 1994).

\section{Stage Two: Neurochemical Sensitization}

This deficiency in neuronal modulatory capacity leads to the second pathophysiological stage that occurs in adolescence and early adulthood. In the course of maturation during this period, stressful, but normative human experiences (e.g., family strife, going to college, entering military service, substance abuse), stimulate perturbations in neuronal activity that would otherwise be compensated for, and equilibrium reestablished, but now progressively result in neurochemical sensitization. This process underlies the prodromal, onset, and deteriorative phases of the illness. A possible reason that the modulatory deficiency does not produce sensitization earlier (in childhood and early adolescence, though in some patients this does occur) may be due to the redundancy in neural synaptic connections that exists through adolescence, which temporarily compensates for the deficiency in modulatory capacity. The deficiency only becomes apparent when, in late adolescence, redundant synaptic connections are eliminated through neural pruning and the circuits refined to the point that the threshold of modulatory capacity is more easily exceedable (Huttenlocher 1979; Feinberg 1982).

Another factor that contributes to the delay in the onset of psychosis in schizophrenia is the need for repetition and intermittency of neurochemical stimulation in response to environmental events (that necessarily accrue over time). Grace $(1991,1993)$ has suggested that 


\section{Neural Circuits in Normal, Sensitized and Neuropathologic Conditions}

Normal Limbic Circuit Response to Acute Stress

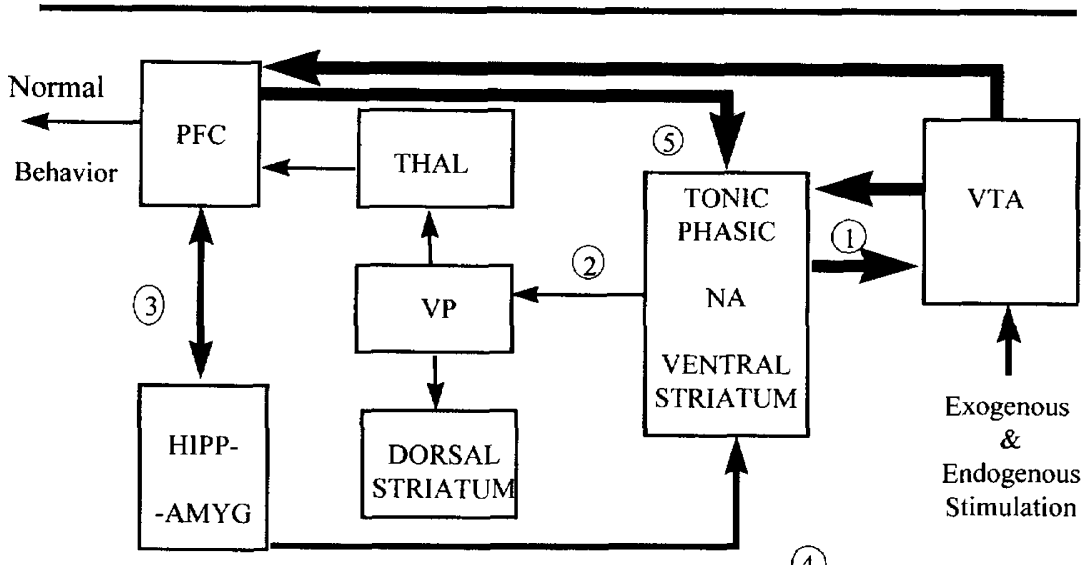

(4)

Figure 1. This figure schematically depicts the limbic circuit and its pattern of activity in response to stressors. The structures include the prefrontal cortex (PFC), ventral tegmental area (VTA), nucleus accumbens (NA), hippocampus (Hipp), amygdala (Amyg), thalamus (Thal), and ventral pallidum (VP). Tonic refers to tonic or non-impulse dependent DA release and phasic refers to impulse dependent DA release. The diagram illustrates how normal stress stimulates the intact mesolimbic-striatal-cortical circuitry and increases activity within the circuit. The focus of this activity is in the nucleus accumbens which requires intact hippocampal afferents for activation and is compensated for by corticostriatal input. The components of this process include: 1) stimulation of output from the ventral tegmental area to the nucleus accumbens by environmental and endogenous stimuli and its feedback inhibition from the nucleus accumbens; 2 ) output from the nucleus accumbens to the ventral pallidum, and dorsal striatum through the thalamus to the cortex; 3) functional interaction of prefrontal cortex and temporolimbic structures (hippocampus and amygdala);4) temporolimbic stimulation of ventral striatum; and 5) feedback from the prefrontal cortex to the nucleus accumbens and tonic inhibition of phasic DA release.

phasic (as opposed to tonic) DA release may be a neurophysiologic correlate in schizophrenia to the intermittency of pharmacologic stimulation, which is a critical factor in DA agonist induced behavioral sensitization. Phasic DA release is dependent on VTA DA neuronal depolarization and impulse activity, and can result in an irregular burst firing pattern of large amplitude and transient increases in DA release (Grace and Bunney 1984). Moreover, DA agonists such as stimulants potentiate impulse dependent DA release (Von Voightlander and Moore 1971) while antipsychotic medications, which appear to interrupt the sensitization process in schizophrenia (Wyatt 1991; Loebel et al. 1992), may exert their therapeutic effects by depolarization induced inactivation of DA cell firing (Bunney and Grace 1978), and is consistent with an interruption of phasic DA release. Furthermore, extracellular electrophysiologic recordings from the DA neurons in the VTA of monkeys have demonstrated that when behaviorally relevant stimuli are presented an increased firing rate occurs, suggesting a pathophysiologic illustration of how stressful life events may result in psychotic relapses in schizophrenia and stimulant induced sensitization (Fabre et al. 1983; Schultz and Romo 1990).

\section{Stage Three: Neurotoxicity}

The third stage underlies the residual phase of the illness and involves the development of structural neuronal changes which are consequential to prolonged sensitization (or effects engendered by it).

\section{Pathophysiology of Sensitization (Stage Two)}

Figures 1-3 illustrate the neuroanatomy of the neuronal systems that are involved in sensitization in normal and pathologic conditions. The nucleus accumbens is the focal point of the process (Morgenson et al. 1993). It is innervated by mesolimbic DA fibers from the VTA and also receives glutamatergic afferents from limbic regions, including the hippocampus, amygdala, and the prefrontal cortex, and provides output through the ventral pallidum to effector sites (see Figure 1).

The activity of accumbal neurons is influenced by phasic synaptic release of DA produced by activation of mesolimbic DA neuron firing in response to behaviorally relevant (or pharmacologic) stimuli, particularly those which are stressful. In addition, tonic DA release from the mesolimbic axon terminal into the extracellu- 


\section{Neural Circuits in Normal, Sensitized and Neuropathologic Conditions}

Sensitized Limbic Circuit Response to Acute Stress

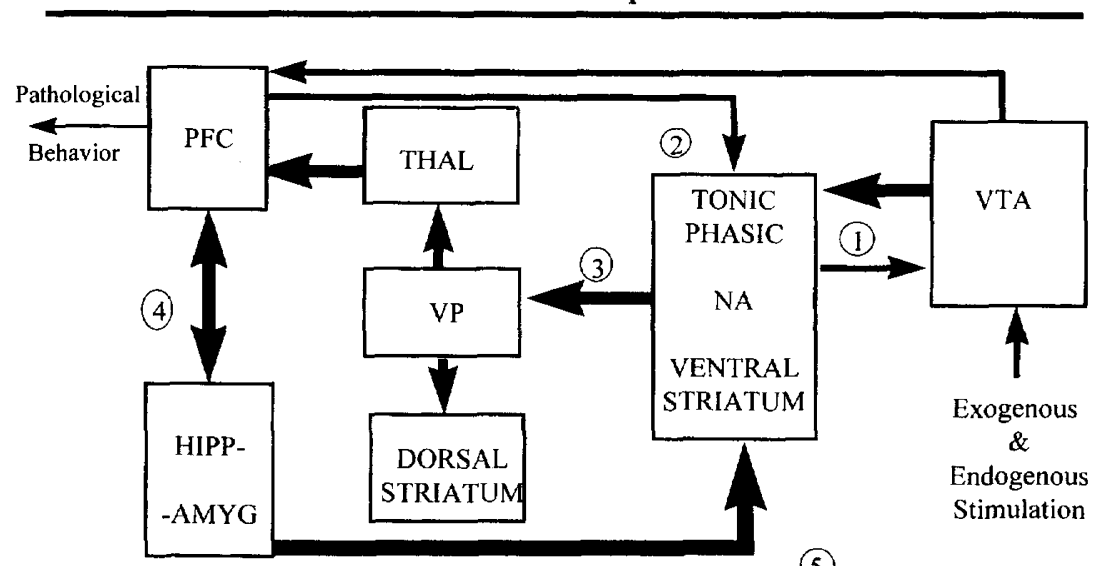

Figure 2. This figure illustrates how extreme or repeated stress or stimulant abuse, in the presence of an intact cortex and limbic circuit, increases ventral tegmental area and nucleus accumbens output activity within the limbic circuit that leads to sensitization giving rise to pathological behavior. In a sensitized limbic circuit ventral tegmental stimulation the nucleus accumbens is unopposed by prefrontal cortical tonic inhibition of phasic DA release due to the uncoupling of these processes (2), and diminished feedback inhibition by the nucleus accumbens of the ventral tegmental neurons (1). This results in increased output from accumbens through the pallidum, and dorsal striatum through the thalamus to the cortex (3). Cortical temporolimbic activity (4), and temporolimbic striatal activity (5) are increased.

lar space acts on presynaptic autoreceptors to inhibit DA synthesis and release, thus modulating phasic DA release. Glutamatergic corticostriatal afferents to the mesolimbic axon terminals also activate tonic DA release. This process can dynamically modulate the amplitude of phasic DA response in subcortical regions, including the striatum and nucleus accumbens, by increasing tonic DA release (Grace 1991).

Stressors of mild intensity or duration selectively activate VTA neurons and produce DA release by mesocortical neurons in the prefrontal cortex, while more intense stressors also increase DA metabolism and release in the nucleus accumbens (Roth et al. 1988). As stress is increased in either intensity or duration, increasing regions of the mesencephalic-cortico-limbic-striato-pallidal pathway will begin to demonstrate an increase in DA activity. These subcortical nuclei can be influenced by stress-induced increases in the firing rates of the mesoprefrontal cortical DA neurons, thus demonstrating the role of prefrontal cortical efferents in affecting DA release (Deutch and Roth 1990; Deutch 1992). This effect can be blocked by administering NMDA antagonists or by lesioning of the amygdala or hippocampus (Yoshikawa et al. 1991; Pert et al. 1992) suggesting that corticostriatal afferents activate stress-induced tonic DA release (Grace 1991).

Repeated exposure to robust stimuli such as environmental stressors or drug challenges can produce long- term changes in the limbic system (see Figure 2). With the repeated stimulations (environmental or pharmacologic) the effectiveness of the feedback system, that normally regulates mesolimbic firing, decreases and behavioral sensitization eventually develops. In this process the inhibition of the accumbens on VTA cell firing is attenuated. This permits an increase in DA cell firing that produces an increase in phasic DA release as well as an increase in tonic DA release. This leads to a pathological induction of a compensatory mechanism in which tonic DA stimulation of autoreceptors becomes uncoupled from phasic DA release. In addition, there is decreased activation of DA release modulating and consequent potentiation of impulse dependant phasic DA release (Grace 1991, 1995). Consequently, impulse dependant phasic DA release is not effectively attenuated. This pathological state then constitutes a new equilibrium between phasic and tonic DA mechanisms and persists even in the absence of further repetitive stimulation. During quiescent periods postsynaptic DA receptors normalize from their previously downregulated (by phasic DA release) condition. Thus, when VTA neurons are again stimulated (by normative, stressful or pharmacologic stimuli) the phasic DA release is enhanced and excessive in the absence of normal inhibitory effects. In a similar fashion, limbic input to these neurons in the absence of effective corticostriatal regulation produces a greater influence on their firing. 


\section{Neural Circuits in Normal, Sensitized and Neuropathologic Conditions}

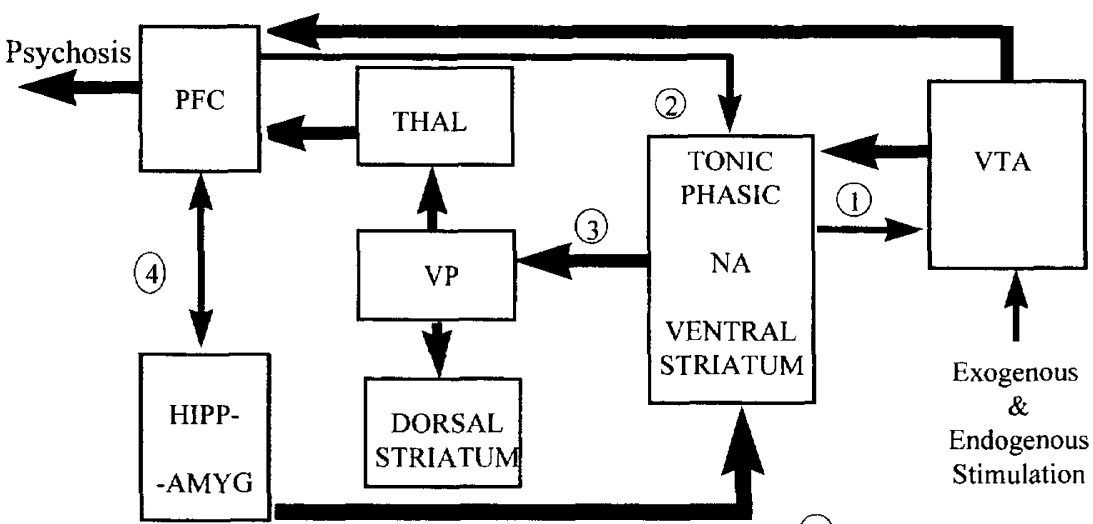

(5)

Figure 3. Normal or extreme stress, in the presence of neuropathology in prefrontal and limbic cortices, increases activity within the limbic circuit that exceeds compensatory capacity and leads to increased ventral tegmental and accumbal activity than sensitization, which ultimately gives rise to psychosis. Shading of the prefrontal cortex and hippocampus amygdala indicates neuropathology. The components of this process are: stimulation of the ventral tegmental area that produces output to the nucleus accumbens (1), which is minimally opposed by cortical striatal inhibition (2) due to cortical deficits. This results in decreased tonic inhibition of phasic DA release in the accumbens (2), increasing accumbens output to the pallidum and dorsal striation (3) through the thalamus to the cortex. This produces increased cortical temporolimbic activity (4) and temporolimbic striatal activity (5) resulting in the expression of pathologic behavior that eventually evolves to psychosis.

This results in a condition of behavioral sensitization which is associated with an increase in DA activity in the nucleus accumbens, and interestingly, a decrease in extracellular DA in the prefrontal cortex. This emphasizes the reciprocal relationship between the regulation of DA release in these 2 regions (Kalivas et al. 1993; Sorg and Kalivas 1993) as has been previously described (Pycock et al. 1980). In addition, since the development of behavioral sensitization to repeated psychostimulants can be prevented by concurrent NMDA antagonist treatment (Karler et al. 1991), or by lesioning of the amygdala or hippocampus (Yoshikawa et al. 1991; Pert et al. 1992) glutamatergic input to the mesolimbic DA system and intact mesolimbic corticostriatal system appears to be required for this phenomenon to occur (Karler et al. 1991) (Figure 2).

A preexisting compromise in corticostriatal and temporolimbic pathways (such as might occur in schizophrenia as a result of the cytoarchitectural pathology) could produce a deficiency of tonic DA release in the nucleus accumbens (see Figure 3 ). Such a condition of deficient corticostriatal glutamatergic innervation has been postulated by several investigators as occurring in schizophrenia by various mechanisms including decreased glutamatergic efferent projections, increased GABA mediated inhibition, target receptor hypofunction (NMDA), or receptor inhibition (e.g., by N-acetyl- aspartylglutamate [NAAG]) (Javitt and Zukin 1991; Carlsson and Carlsson 1990; Grace 1991; Benes 1995b; Olney and Farber 1995; Coyle 1995; Tsai et al. 1995). This would facilitate the potentiation of phasic mesolimbic DA neuron activity, as well as postsynaptic responsivity and the eventual development of sensitization possibly even in the absence of repeated (severe) stressors and DA agonist stimulation (Grace 1991). In this way prefrontal and temporal cortical damage could facilitate the development of behavioral sensitization as it would appear to augment the mesolimbic response to stress as well as possibly to stimulant drugs.

Evidence consistent with this has been reported by Weinberger and colleagues (1995). Chemical deafferentiation of the prefrontal cortex by excitotoxin injection produced no significant alteration in basal DA levels or turnover in the basal ganglia or in DA-related behaviors, yet it did result in markedly elevated DA mesolimbic activity when the animals were exposed to stressful stimuli (Jaskiw et al. 1990). Similar results have been found after surgical ablation of the prefrontal cortex. Therefore, animals with a functionally compromised prefrontal cortex have been found to experience relatively trivial environmental stresses as if they were lifethreatening (Lipska and Weinberger 1993b).

The amygdala and hippocampus also regulate subcortical DA activity (Rada and Hernandez 1990; Lipska 
et al. 1992). Rats with neonatal ventral hippocampal deafferentiation, when tested after puberty, are hyperresponsive to environmental stress as are adults with prefrontal cortex lesions. This finding suggests that the loss of hippocampal-prefrontal cortical connections may critically disrupt the normal development and connectivity of the limbic stress circuit (Lipska et al. 1992). Further support of the role of the hippocampus in regulating subcortical activity is provided by the results of a study of synaptic interactions among excitatory afferents to the nucleus accumbens in rats via in vivo intracellular recordings (O'Donnell and Grace 1995). Hippocampal input was necessary for accumbens neurons to enter a depolarized, active state, whereas activation of prefrontal cortical inputs failed to evoke spike firing in accumbens neurons unless they were in the active state.

In summary, the mesiotemperal and prefrontal cortical neuropathology (gross morphologic and cytoarchitectural) that occur in schizophrenia could produce a pathological decrease in prefrontal cortical activity that results in a prolonged decrease in tonic extracellular DA levels within the nucleus accumbens. This would ultimately lead to schizophrenia patients experiencing abnormally large phasic DA responses to behaviorally relevant stimuli (Grace 1991). This process would explain a number of clinical phenomena including the pathogenesis of the illness onset, the association between psychotic episode duration and number and treatment response, and the enhanced sensitivity to stress and psychostimulants that patients with schizophrenia have (Figure 3).

The phasic DA release which is suggested for the expression of the neurochemical sensitization in schizophrenia, if analogous to animal models of behavioral sensitization, would result in excitatory amino acid receptor (EAA) activation. As previously reviewed, systemic administration of NMDA antagonists can block the induction of sensitization from psychostimulants, as does lesioning of the afferent glutamatergic fibers from the hippocampus to the nucleus accumbens, or injection of NMDA antagonists into the amygdala or VTA. Thus, we hypothesize further that through this functional interaction of the DA and glutamatergic systems, following a sustained period of sensitization and enhanced DA neuronal activity, a third stage involving elevated levels of cortico-striatal EAA activity may develop, resulting in a self limiting neurotoxicity. Consistent with the neuroexcitatory action of the EAAs which are involved in normative CNS functions is a paradoxical phenomenon of excitotoxicity (Olney 1989; Olney and Farber 1995) whereby a neuropathologic process may develop if EAA receptor stimulation becomes excessive. EAA induced brain damage has been suggested as the mechanism underlying the neurodegeneration resulting from sustained temporal lobe seizures, hypoxia/ischemia (Choi and Rothman 1990) and Huntington's disease (Olney et al. 1990; Choi 1988). In addition to EAA excitotoxicity, sensitization of DA neurons could also involve mechanisms of oxidative stress (Coyle and Puttfarcken 1993).

Therefore, a diminished compensatory response from the prefrontal cortex may result in the vulnerability to dysregulation of DA cell bodies in the VTA leading to excessive firing and further EAA activation and neuronal injury until blocked by antipsychotic drugs. However, there is neither consistent evidence for neurotoxicity in schizophrenia (primarily in the form of gliosis or decreased neuronal number) nor animal models of behavioral sensitization of neurotoxicity (with the exception of after high dose methamphetamine administration (Seiden and Vosmer 1984). Recently, however, it has been suggested that EAA mediated neurotoxicity can occur by a more gradual nonflorid process involving an apoptotic mechanism of programmed cell death or loss of cell processes rather than the more commonly described fulminant process that would be expected to produce gliosis (Coyle 1995; Olney and Farber 1995). This process would explain the development of persistent symptomatology including negative symptoms and the deficit state that are resistant to antipsychotic drugs.

\section{OTHER NEUROPSYCHIATRIC SYNDROMES}

Given that mechanisms of neuronal plasticity such as sensitization are generic properties of neurons, we could reasonably expect that there should be evidence of similar processes occurring in other neuropsychiatric disorders, albeit requiring a higher threshold for their precipitation than exists in schizophrenia. Studies of major affective disorders, which have been hypothesized to be on a pathologic continuum with schizophrenia (Crow 1990b), suggest a pattern consistent with sensitization. This subject has been extensively reviewed (Post et al. 1986). They conclude that bipolar and unipolar affective illness tend to be recurrent; the frequency of recurrence and increases in episodes of rapid cycling are associated with both increased age and number of prior episodes; symptoms are continuously manifest across episodes, with new symptoms developing in addition to the ones which had occurred in prior episodes; later occurring episodes may have more precipitous onsets than earlier episodes; and psychosocial stress often results in the onset of an episode (Post 1992b). As a consequence therapeutic considerations will differ over the course of the illness with continued maintenance treatment being required in the later stages (Greden and Tandon 1995).

Temporal lobe epilepsy (TLE), frequently associated with comorbid psychiatric disorders (psychotic and affective) (Umbricht et al. 1995), has been attributed to a kindling like pathophysiologic process (Stevens 1988). 
A number of studies have implicated the hippocampus and limbic structures in TLE (Sutula 1990), areas that we hypothesize to be necessary for the induction of behavioral sensitization. These brain regions are particularly vulnerable to activation with high frequency trains of stimulation. The electrical stimulation, while at first subthreshold for seizures, will increase after discharges and eventually result in major motor convulsions (Sutula 1990). Though the cellular mechanisms underlying TLE are not fully understood, the EAAs are believed to play central roles in its pathogenesis (Mody 1993; Kiessling and Gass 1993). It is striking that the temporal lobe, and specifically mesiotemporal structures, have become a major neuropathologic focus in schizophrenia. The presence of structural and functional (event related potential measures of cognition) abnormalities in the temporal lobe have consistently been reported in schizophrenia patients (Bogerts et al. 1990, 1993; Bogerts 1993; Barta et al. 1990; McCarley et al. 1991, 1993; Crow 1990a; Shenton et al. 1992; Javitt et al. 1994).

Posttraumatic stress disorder (PTSD) consists of a pattern of symptoms lasting at least one month that occurs following exposure to a severe trauma that involved intense fear, hopelessness, or horror, and results in clinically significant distress or impairment. PTSD may result from a one time stressor though it is more likely to occur if the stressor is prolonged and repetitive (Tomb 1994). PTSD may follow a fluctuating course with symptoms that have been in remission for an extended period of time recurring in the presence of a minor stress, a symbolic occurrence of the original stress, or for no recognizable reason (Kinzic 1993). Based on the enduring nature of the phenomenon, the decrease in stress tolerance, and the exaggerated startle response, it has been hypothesized that some of the phenomenology of PTSD are consistent with a sensitization model (Charney et al. 1993; Southwick et al. 1994). This is supported by studies demonstrating increased rates of PTSD following combat exposure among veterans who were traumatized in childhood (Bremmer 1993), or who had suffered acute stress reactions in previous wars (Solomon et al. 1987; Solomon 1989). Furthermore, in addition to the generalized state of hyperarousal among PTSD patients, combat veterans exposed to visual and auditory combat related stimuli had greater elevations in heart rate compared to veterans without PTSD (Orr 1990). The specific neural mechanisms underlying the full spectrum of symptoms in PTSD are unknown, however, the exaggerated startle and hypervigilance are hypothesized to be due to hyperactivity in the regulation of synaptic DA (Charney et al. 1993). This has led to a concern that amphetamine or cocaine use among PTSD patients may result in an increased risk for the development of paranoia or psychosis, a similar concern that has been raised regarding the use of psychostimulants among schizophrenia patients (Selzer and Lieberman 1993).

The drug addiction associated with substance abuse has also been proposed to involve disturbances in neuronal plasticity including sensitization (Robinson and Berridge 1993; Nestler et al. 1993). Although some aspects of drug addiction can occur rapidly with acute administration, most changes in brain function that underlie addiction occur gradually over time. These are believed to involve progressive developing and persistent adaptations of biochemical function in two anatomic regions, the mesolimbic DA system (Koob 1992) and noradrenergic neurons in the locus ceruleus (McDougle et al. 1994). Chronic opiate and/or stimulant administrations produce a chain of biochemical alterations involving neurotransmitter synthesis and turnover (increased tyrosine hydroxylase activity), DA receptors (increased D-1 sensitivity), cAMP dependent protein kinase, early immediate gene response (cFOS, cJUN) and cAMP response element binding protein (CREB).

The treatment of drug addiction has been largely unsuccessful. Robinson and Berridge (1993) attribute part of this failure to a psychological process they term 'incentive salience', whereby the drugs themselves or the events surrounding drug use can result in a sensitization of DA neural systems. Therefore, an ordinary desire for drugs can be turned into excessive drug craving via the sensitization of the mechanisms underlying 'incentive salience', These authors further postulate that the neural systems responsible for the sensitization of the 'incentive salience' are independent of the neural mechanisms underlying the pleasurable, or the withdrawal effects of the drugs.

\section{PREDICTIONS AND TESTS OF THE HYPOTHESIS}

A number of specific predictions can be derived from the proposed hypothesis: 1) Longer duration of psychoses would be associated with poorer treatment response, higher levels of residual symptoms and morbidity; 2) Patients will exhibit greater sensitivity to stress and psychostimulants in the earlier phases of the illness; 3 ) More severe forms of psychopathology (e.g., deficit state, disorganized and catatonic symptoms) would be associated with longer durations of psychoses and occur in the latter stages of the illness; 4) Antipsychotic treatment resistance would develop over the course of the illness and be most prevalent in the latter stages; 5) Increased levels of presynaptic and extracellular DA could be demonstrated in patients with schizophrenia particularly in the early phases; 6) Brain neuropathology of structures containing DA and glutamate terminal field regions would be progressive and associated with longer duration of psychoses; and 7) Treatment interventions that 
limit duration and number of psychotic episodes will prevent the development of treatment resistance, severe forms of psychopathology, progression of brain neuropathology, and reduce the likelihood of tardive dyskinesia. Thus, this hypothesis can be tested through clinical investigation and confirmed or disproven.

Although some of these predictions contributed to the hypothesis' derivation, their replication in future studies and new samples would be additional tests of validity.

\section{CONCLUSION}

We have hypothesized that the pathophysiological processes in schizophrenia unfold in 3 stages over the life of the patient and corresponds to specific phases of the illness. The initial developmental insult to the CNS (stage 1) does not result in psychosis until a combination of developmental and dysregulatory events occur causing sensitization (stage 2) which then can lead to the formal onset of illness which if persistent or recurrent can progress to a self limiting degenerative phase (stage 3 ) manifested by persistent morbidity, treatment resistance, and clinical deterioration. While our hypothesis does not address the question of etiology, it is compatible with the major etiologic theories. This model attempts to account for the clinical phenomena of the illness and its longitudinal course. Although clearly speculative, it is, we believe, reasonably supported by existing evidence, particularly for the second stage involving neurochemical sensitization. Furthermore, the deterioration evident in the course and outcome of some schizophrenia patients may be the result of a progressively diminishing capability of CNS homeostatic mechanisms. An understanding of the mechanisms which mediate the brain's endogenous ability to maintain homeostasis and prevent abnormal functions that can give rise to symptom expression, may offer alternative approaches to the eludication and future treatment of this disorder.

\section{ACKNOWLEDGMENT}

This work was supported by The Hillside Hospital (MH 41960) and UNC (MH 33127) MHCRCs and a NIMH Research Scientist Development Award (MH-00537) to Dr. Lieberman. The authors appreciate the helpful and constructive comments of Will Carpenter, M.D., John Waddington, Ph.D., Thomas McGlashan, M.D., Robert Bilder, Ph.D. and the reviewers of the article in its development and revision.

\section{REFERENCES}

Akbarian S, Kim JJ, Potkin SG, Hagman JO, Tafazzoli A, Bunney WE Jr, Jones EG (1995): Gene expression for glutamic acid decarboxylase is reduced without loss of neurons in prefrontal cortex of schizophrenics. Arch Gen Psychiatry 52(4):258-278

Akbarian S, Bunney WE Jr., Potkin SG, Wigal SB, Hagman, JO, Sandman CA, Jones EG (1993a): Altered distribution of nicotinamide-adenine dinucleotide phosphate-diaphorase cells in frontal lobe of schizophrenics implies disturbances of cortical development. Arch Gen Psychiatry 50(3):169-177

Akbarian S, Vinuela A, Kim JJ, Potkin SG, Bunney WE Jr, Jones EG (1993b): Distorted distribution of nicotinamide-adenine dinucleotide phosphate-diaphorase neurons in temporal lobe of schizophrenics implies anomalous cortical development. Arch Gen Psychiatry 50(3):178-187

Alberini CM, Ghiradi M, Metz R, Kandel ER (1994): C/EMP is an immediate early gene required for the consolidation of long term facilitation in the aplasia. Cell 76(6): 1099-1114

American Psychiatric Association (1994): Diagnostic and Statistical Manual of Mental Disorders, 4th ed. Washington, DC, American Psychiatric Press

Anderson SA, Volk DW, Lewis DA (1995): Increased density of microtubule associated protein 2-immunoreactive neurons in the prefrontal white matter of schizophrenic subjects. Schizophr Res 19:111-119

Andreasen NC, Arndt S, Alliger R, Miller D, Flaum M (1995): Symptoms of schizophrenia: methods, meanings and mechanisms. Arch Gen Psychiatry 52(5):341-351

Andreasen NC, Carpenter WT Jr (1993): Diagnosis and classification of schizophrenia. Schizophr Bull 19(2):199-214

Angrist BM, Gershon S (1970): The phenomenology of experimentally induced amphetamine psychosis-preliminary observation. Biol Psychiatry 2:95-107

Angrist BM, Sathananthan G, Wilk S, Gershon S (1974): Amphetamine psychosis: behavioral and biochemical aspects. J Psychiatr Research 11:13-23

Angrist B, Rotrosen J, Gershon S (1980): Responses to apomorphine, amphetamine, and neuroleptics in schizophrenic subjects. Psychopharmacology 67:31-88

Antelman SM, Eichler AJ, Black CA, Kocan D (1980): Interchangeability of stress and amphetamine in sensitization. Science 207(4428):329-331

Antelman SM, Kocan D, Edwards DJ, Knopf S, Perel JM, Stiller R (1986): Behavioral effects of a single neuroleptic treatment grow with the passage of time. Brain Res 385(1):58-67

Arnold SE, Franz BR, Gur RC, Gur RE, Shapiro RM, Moberg PJ, Trojanowski JQ (1995): Smaller neuron size in schizophrenia in hippocampal subfields that mediate cortical-hippocampal interactions. Am J Psychiatry 152(5):738-748

Bailey CH, Chen M (1983): Morphological basis of long term habituation and sensitization in Aplasia. Science 220:91-93

Barta PE, Pearlson GD, Powers RE, Richards SS, Tune LE (1990): Auditory hallucinations and smaller superior temporal gyral volume in schizophrenia. Am J Psychiatry $147(11): 1457-1462$

Benes FM (1995a): Is there a neuroanatomic basis for schizophrenia? An old question revisited. The Neuroscientist 1(2):104-115 
Benes FM (1995b): Development of the glutamate, GABA and dopamine systems in relation to $\mathrm{NRH}$-indiced neurotoxicity. Biol Psychiatry 38(12):783-787

Bloom FE (1993): Advancing a neurodevelopmental origin for schizophrenia. Arch Gen Psychiatry 50(3):224-227

Bogerts B (1993): Recent advances in the neuropathology of schizophrenia. Schizophr Bull 19(2):431-445

Bogerts B, Lieberman JA, Ashtari M, Bilder R, Degreef G, Lerner G, Johns C, Masiar S (1993): Hippocampusamygdala volumes and psychopathology in chronic schizophrenia. Biol Psychiatry 33:236-246

Bogerts B, Ashtari M, Degreef G, Alvir JM, Bilder RM, Lieberman JA (1990): Reduced temporal limbic structure volumes on magnetic resonance images in first episode schizophrenia. Psychiatr Res 35(1):1-13

Bracha HS, Torrey EF, Bigelow LB, Lohr JB, Linington BB (1991): Subtle signs of prenatal maldevelopment of the hand ectoderm in schizophrenia: A preliminary monozygotic twin study. Biol Psychiatry 30:719-725

Braff D, Stone C, Callaway E, Glick I, Bali L (1978): Prestimulus effects on human startle reflex in normals and schizophrenics. Psychophysiology 15(4):339-343

Breier A, Su TP, Saunders R, Carson RE, Kolachana BA, de Bartolomeis A, Weinberger DR, Weisenfeld N, Malhotra AK, Eckelman WC, Pickar D (1997): Schizophrenia is associated with elevated amphetamine-induced synaptic dopamine concentrations: evidence from a novel positron emission tomography method. Proceedings of the National Academy of Sciences 94(6):2569-2574

Bremner JD, Southwick SM, Johnson DR, Yehuda R, Charney DS (1993): Childhood abuse in combat-related posttraumatic stress disorders. Am J Psychiatry 150(2):235-239

Bunney BS, Grace AA (1978): Acute and chronic haloperidol treatment: comparison of effects on nigral dopaminergic cell activity. Life Sci 23:1715-1728

Cain DP (1989): Long term potentiation and kindling: how similar are the mechanisms? Trends Neurosci 12(1):6-10

Carlsson M, Carlsson A (1990): Interactions between glutamatergic and monoaminergic systems within the basal ganglia-implications for schizophrenia and Parkinson's disease. Trends Neurosci 13(7):272-276

Carpenter, WT Jr, Buchanan RV, Kirkpatrick B, Tamminga C, Wood F (1993): Strong inference, theory testing, and the neuroanatomy of schizophrenia. Arch Gen Psychiatry 50:825-831

Carpenter WT Jr, Kirkpatrick B (1988): The heterogeneity of the long term course of schizophrenia. Schizophr Bull 14(4):645-652

Carpenter WT, Buchanan RW, Breier A, Kirkpatrick B, et al. (1991): Psychopathology and the question of neurodevelopmental or neurodegenerative disorder. Schizophr Res 5(3):192-194

Charney DS, Deutch AY, Krystal JH, Southwick SM, Davis M (1993): Psychobiologic mechanisms of posttraumatic stress disorder. Arch Gen Psychiatry 50:294-305

Chevalier G, Deniau JM (1990): Disinhibition as a basic process in the expression of striatal functions. Trends Neurosci 13(7):277-280

Choi DW, Rothman SM (1990): The role of glutamate neuro- toxicity in hypoxic-ischemic neuronal death. Annu Rev Neurosci 13:171-182

Choi DW (1988): Glutamate neurotoxicity and diseases of the nervous system. Neuron 1:623-634

Coppens HJ, Slooff CJ, Paans AMJ, Wiegman T, Vallburg W, Korf J (1991): High central D2-dopamine receptor occupancy as assessed with positron emission tomography in medicated but therapy-resistant schizophrenic patients. Biol Psychiatry 29(7):629-634

Costall B, Naylor RJ (1977): Mesolimbic and extrapyramidal sites for the mediation of stereotyped behavior patterns and hyperactivity by amphetamine and apomorphine in the rate. Advances in Behavior and Biology 21:47-76

Cotman CW, Monaghan DT, Ganong AH (1988): Excitatory amino acid neurotransmission: NMDA receptors and Hebb-type synaptic plasticity. Annu Rev Neurosci 11: $61-80$

Coyle JT (1995): Glutamate, oxidative stress and schizophrenia. 5th International Congress on Schizophrenia Research. Hot Springs, Virginia

Coyle JT, Puttfarcken P (1993): Oxidative stress, glutamate, and neurodegenerative disorders. Science 262(5134): 689-695

Creese I, Burt DR, Snyder SH (1976): Dopamine receptor binding predicts clinical and pharmacological potencies of antischizophrenic drugs. Science 192:480-483

Crow TJ (1990a): Temporal lobe asymmetries as the key to the etiology of schizophrenia. Schizophr Bull 16(3):433-443

Crow TJ (1990b): The continuum of psychosis and its genetic origins. Br J Psychiatry 156:788-797

Crow TJ, MacMillan JF, Johnson AL, Johnstone EC (1986): A randomised controlled trial of prophylactic neuroleptic treatment. Br J Psychiatry 148:120-127

Crow TJ (1985): The two-syndrome concept:origins and current status. Schizophr Bull 11(3):471-486

Crow TJ (1980): Molecular pathology of schizophrenia: more than one dimension of pathology? BMJ 280:66-68

Csernansky JG, Bellows EP, Barnes DE, Lombrozo L (1990): Sensitization versus tolerance to the dopamine turnover elevating effects of haloperidol: the effect of regular/ intermittent dosing. Psychopharmacology(Berl) 101(4): 519-524

Csernansky JG, Mellentin J, Beauclair L, Lombrozo L (1988): Mesolimbic dopaminergic supersensitivity following electrical kindling of the amygdala. Biol Psychiatry 23: 285-294

Davis KL, Kahn RS, Ko G, Davidson M (1991): Dopamine in schizophrenia: a review and reconceptualization. Am J Psychiatry 148(11):1474-1486

Daviss SR, Lewis DA (1995): Local circuit neurons of the prefrontal cortex in schizophrenia: selective increase in the density of calbindin-immunoreactive neurons. Psychiat Res 59:81-96

Deutch AY (1992): The regulation of subcortical dopamine systems by the prefrontal cortex: interactions of central dopamine systems and the pathogenesis of schizophrenia. J Neural Transm Suppl 36:61-89

Done DJ, Crow TJ, Johnstone EC, Sacker A (1994): Childhood 
antecedents of schizophrenia and affective illness: social adjustment at ages 7 and 11. BMJ 309:699-703

Dragunow M, Robertson GS, Faull RL, Robertson HA, Jansen K (1990): D2 dopamine receptor antagonists induce fos and related proteins in rat striatal neurons. Neuroscience 37(2):287-294

Dragunow M, Currie RW, Faull LM, Robertson HA, Jansen K (1989): Immediate-early genes, kindling and long term potentiation. Neurosci Biobehav Rev 13:301-313

Ellinwood EH Jr (1971): "Accidental conditioning" with chronic methamphetamine intoxication: implications for a theory of drug habituation. Psychopharmacologia(Berl) 21(2):131-138

Erlenmeyer-Kimling L, Cornblatt B (1987): High-risk research in schizophrenia: A summary of what has been learned. J Psychiatr Res 21(4):401-411

Fabre M, Rolls ET, Ashton JP, Williams G (1983): Activity of neurons in the ventral tegmental area of the behaving monkey. Behavior and Brain Research 9:213-235

Farde L, Wiesel FA, Stone-Elander S, Halldin C, Nordstrom AL, Hall H, Sedvall G (1990): D2 dopamine receptors in neuroleptic-naive schizophrenic patients. A positron emission tomography study with [11C] raclopride. Arch Gen Psychiatry 47(3): 213-219

Farde L, Ginovart N, Halldin C. PET-study on D2-receptors in reserpine depleted primates. Presented at the 35 th Annual Meeting American College of Neuropsychopharmacology, San Juan, Puerto Rico, December 9-13, 1996 , p. 25

Feinberg I (1982): Schizophrenia: caused by a fault in programmed synaptic elimination during adolescence? J Psychiatr Res 17:319-334

Fish B (1977): Neurobiologic antecedents of schizophrenia in children: Evidence for an inherited, congenital neurointegrative defect. Arch Gen Psychiatry 34:1297-1313

Friedman MJ (1944): Neurobiological sensitization models of post-traumatic stress disorders: their possible relevance to multiple chemical sensitivity syndrome. Toxicol Ind Health $10(4-5): 449-462$

Fujiwara Y, Kazahya Y, Nakashima M, Sato M, Otsuki S (1987): Behavioral sensitization to methamphetamine in the rat: an ontogenic study. Psychopharmacology 91: 316-319

Gersons BR, Carlier IV (1992): Post-traumatic stress disorder: The history of a recent concept. Br J Psychiatry 161:742-748

Giros B, Jaber M, Wightman RM, Caron M (1996): Hyperlocomotion and indifference to cocaine and amphetamines in mice lacking the dopamine transporter. Nature (379): 606-612

Glenthoj B, Hemmingsen R, Allerup P, Bowlig TG (1990): Intermittent versus continuous neuroleptic treatment in a rat model. Eur J Pharmacol 190(3):275-286

Glenthoj B, Hemmingsen R, Barry DI, Allerup P, Bruhn T, Bolwig TG (1993a): Electrical kindling of rats treated discontinuously or continuously with haloperidol. Eur J Pharmacol 236(3):401-409

Glenthoj B, Mogensen B, Laursen H, Holm S, Hemmingsen R (1993b): Electrical sensitization of the meso-limbic dopaminergic system in rats: a pathogenetic model for schizophrenia. Brain Res 619:39-54
Goddard GV (1967): Development of epileptic seizures through brain stimulation at low intensity. Nature 214:1020-1021

Goddard GV, McIntyre DC, Leech DK (1969): A permanent change in brain function resulting from daily electrical stimulation. Experimental Neurology 25(3):295-330

Goelet P, Castellucci VF, Schacher S, Kandel ER (1986): The long and the short of long-term memory-a molecular framework. Nature 322(32):419-422

Grace AA (1995): The tonic/phasic model of dopamine system regulation: Its relevance for understanding how stimulant abuse can alter basal ganglia function. Drug Alcohol Depend 37:111-129

Grace AA (1993): Cortical regulation of subcortical dopamine systems and its possible relevance to schizophrenia. J Neural Transm 91:111-134

Grace AA (1991): Phasic versus tonic dopamine release and the modulation of dopamine system responsivity: a hypothesis for the etiology of schizophrenia. Neuroscience $41(1): 1-24$

Grace AA, Bunney BS (1984): The control of firing pattern in nigral dopamine neurons: burst firing. J Neurosci 4(11):2877-2890

Greden JF, Tandon R (1995): Long-term treatment for lifetime disorders? Arch Gen Psychiatry 52(3):197-200

Green MF, Bracha HS, Satz P, Christenson CD (1994): Preliminary evidence for an association between minor physical anomalies and second trimester neurodevelopment in schizophrenia. Psychiatry Res 53(2):119-127

Greenberg SM, Castellucci VF, Bayley H, Schwartz JH (1987): A molecular mechanism for long term sensitization in Aplasia. Nature 329:62-65.

Griffith JD, Cavanaugh J, Oates J (1968). Paranoid episodes induced by drug. JAMA 205(11):39

Gur RE, Mozky D, Resnick S, Mosley L, Shastel D, Gallacher F, Arnold S, Karp J, Alari A, Revich M, Gur RC (1995): Resting cerebral glucose metabolism in first-episode and treated patients with schizophrenia. Arch Gen Psychiatry 52:657-667

Hafner H, Maurer K, Loffler W, Riecher-Rossler A (1993): The influence of age and sex on the early course of schizophrenia. Br J Psychiatry 162:80-86

Hamamura T, Fibiger HC (1993): Enhanced stress induced dopamine release in the prefrontal cortex of amphetamine sensitized rats. Eur J Pharmacol 237(1):65-71

Hasselmo ME (1995): Neuromodulation and cortical function: Modeling the physiological basis of behavior. Behav Brain Res 67:1-27

Hebb DO (1949): The Organization of Behavior: A Neurophysiological Theory. New York, Wiley

Hedner TH, Lundborg P (1985): Development of dopamine autoreceptors in the postnatal rat brain. J Neural Transm 62:53-63

Hierholzer R, Munson J. Peabody C, Rosenberg J (1992): Clinical presentation of PTDS in World War II combat veterans. Hosp Community Psychiatry 43(8):816-820

Hommer DW, Pert A (1983): The action of opiates in the rat substantia nigra: an electrophysiological analysis. Peptides 4:603-608 
Hooks MS, Jones GH, Liem BJ, Justice JB Jr (1992): Sensitization and individual differences to IP amphetamine, cocaine, or caffeine following repeated intracranial amphetamine infusions. Pharmacol Biochem Behav 43(3):815823

Huber G, Gross G, Schuttler R, Linz M (1980): Longitudinal studies of schizophrenic patients. Schizophr Bull 6(4):592605

Hurd YL, Weiss F, Koob GF, Ungerststedt NEU (1989): Cocaine reinforcement and extracellular dopamine overflow in rat nucleus accumbens: an in vivo microdialysis study. Brain Res 498:199-203

Huttenlocher PR (1979): Synaptic density in the human frontal cortex- developmental changes and the effects of aging. Brain Res 163:195-205

Illowsky BP, Juliano DM, Migelow LB, Weinberger DR (1988): Stability of CT scan findings in schizophrenia: results of an 8 year follow-up study. J Neurol Neurosurg Psychiatry 51(2):209-213

Innis RB, Malison RT, al-Tikriti M, Hoffer PB, Sybirska EH, Seibyl JP, Zoghbi SS, Baldwin RM, Laruelle M, Smith EO (1992): Amphetamine-stimulated dopamine release competes in vivo for [123I]IBZM binding to the D2 receptor in nonhuman primates. Synapse 10(3):177-184

Iwanami A, Sugiyama A, Kuroki N, Toda S, Kato N, Nakatani Y, Horita N, Kaneko T (1994): Patients with methamphetamine psychosis admitted to a psychiatric hospital in Japan. A preliminary report. Acta Psychiatrica Scandinavica $89(6): 428-432$

Jackson JH (1931): Selected Writings of John Hughlings Jackson. Vol 1. Taylor J (ed). London, Hodder and Stoughton

Jakob H, Beckmann H (1986): Prenatal developmental disturbances in the limbic allocortex in schizophrenics. J Neural Transm 65(3-4):303-326

Janowsky DS, el-Yousel MK, Davis JM, Sekerke HJ (1973): Provocation of schizophrenic symptoms by intravenous administration of methylphenidate. Archives of General Psychiatry 28(2):185-191

Janowsky DS, Davis JM (1976): Methylphenidate, dextroamphetamine, and levamphetamine. Effects on schizophrenia symptoms. Arch Gen Psychiatry 33:304-308

Jaskiw GE, Karoum F, Weinberger DR (1990): Persistent elevations in dopamine and its metabolites in the nucleus accumbens after mild subchronic stress in rats with ibotenic acid lesions of the medial prefrontal cortex. Brain Res 534:321-323

Javitt DC, Zukin SR (1991): Recent advances in the phencyclidine model of schizophrenia. Am J Psychiatry 148(10): 1301-1308

Javitt DC, Steinschneider M, Schroeder CE, Vaughan HG, Arezzo JC (1994): Detection of stimulus deviance within primate primary auditory cortex: intracortical mechanisms of mismatch negativity generation. Brain Res 667(2):192-200

Jeziorski M, White FJ, Wolf ME (1994): MK-801 prevents the development of behavioral sensitization during repeated morphine administration. Synapse 16:137-147

Johns JM, Noonan LR (1995): Prenatal cocaine exposure affects social behavior in Sprague-Dawley rats. Neurotoxicology and Teratology 17(5):569-576
Kalivas PW, Stewart J (1991): Dopamine transmission in the initiation and expression of drug and stress induced sensitization of motor activity. Brain Res Rev 16:223-244

Kalivas PW (1993a): Time course of extracellular dopamine and behavioral sensitization. II. Dopamine perikarya. J Neurosc 13(1):276-284

Kalivas PW (1993b): Involvement of N-methyl-D-aspartate receptor stimulation in the ventral tegmental area and amygdala in behavioral sensitization to cocaine. J Pharmacol Exp Ther 267(1):486-495

Kalivas PW (1993c): Neurotransmitter regulation of dopamine neurons in the ventral tegmental area. Brain Res Rev 18(1):75-113

Kalivas PW (1993d): Time course of extracellular dopamine and behavioral sensitization to cocaine. I. Dopamine axon terminals. J Neurosci 13(1):266-275

Kalivas PW, Churchill L, Klitenick MA (1993): The circuitry mediating the translation of motivational stimuli into adaptive motor response. In Kalivas PW, Barnes CD (eds), Limbic Motor Circuits and Neuropsychiatry. Boca Raton, CRC Press, pp 237-287

Kandel ER (1991): Cellular mechanisms of learning and the biological basis of individuality. In Kandel ER, Schwartz JH, Jessell TM (eds), Principles of Neural Science, 3rd ed. New York, Elsevier

Kandel ER, Schwartz JH (1982): Molecular biology of learning: Modulation of transmitter release. Science 218:433-443

Kane JM, Lieberman JA (1987): Maintenance pharmacotherapy in schizophrenia. In Meltzer HY (ed), Psychopharmacology: the 3rd Generation of Progress. New York, Raven Press, pp 1103-1109

Karler R, Calder LD, Turkanis SA (1991): DNQX blockade of amphetamine behavioral sensitization. Brain Res 552: 295-300

Kendler KS, Diehl SR (1993): The genetics of schizophrenia: a current, genetic-epidemiologic perspective. Schizophr Bull 19(2):261-285

Kerwin RW (1994): The new atypical antipsychotics. A lack of extrapyramidal side-effects and new routes in schizophrenia research. Br J Psychiatry 164:141-148

King GR, Joyner C, Lee T, Kuhn C, Elinwood EH Jr. (1992): Intermittent and continuous cocaine administration: Residual behavioral states during withdrawal. Pharmacol Biochem Behavior 43:342-348

Kinzie JD (1993): Posttraumatic effects and their treatment among southeast Asian refugees. In Wilson JP, Raphael B (eds), International Handbook of Traumatic Stress Syndromes. New York, Plenum Press, pp 311-319

Kirkby RD, Kokkinidis L (1987): Evidence for a relationship between amphetamine sensitization and electrical kindling of the amygdala. Exp Neurol 97(2):270-279

Kirch DG (1993): Infection and autoimmunity as etiologic factors in schizophrenia: A review and reappraisal Schizophr Bull 19(2):355-370

Kolta MG, Scalzo FM, Ali SF, Holson RR (1990): Ontogeny of the enhanced behavioral response to amphetamine in amphetamine-pretreated rats. Psychopharmacol 100: 377-382

Koob GF (1992): Drugs of abuse: anatomy, pharmacology 
and function of reward pathways. Trends Pharmacol Sci 13:177-184

Kovelman JA, Scheibel AB (1984): A neurohistological correlate of schizophrenia. Biol Psychiatry 19(12):1601-1621

Kraepelin E (1919): Dementia Praecox and Paraphrenia. Barkley RM, Robertson GM (eds). Edinburgh, Scotland, E. and S. Livingstone. 1971

Lacey MG, Mercuri NB, North RA (1989): Two cell types in rat substantia nigra zona compacta distinguished by membrane properties and the actives of dopamine and opoids. J Neurosci 9:1233-1241

Laruelle M, Abi-Dargham A, van Dyck CH, Gil R, D'Souza CD, Erdos J, McCance E, Rosenblatt W, Fingado C, Zoghbi SS, Baldwin RM, Seibyl JP, Krystal JH, Charney DS, Innis RB (1996): Single photon emission computerized tomography imaging of amphetamine-induced dopamine release in drug-free schizophrenic subjects. Proceedings of the National Academy of Sciences 93(17):9235-9240

Levy AD, Kim JJ, Ellison GD (1988): Chronic amphetamine alters D2 but not D1 agonist induced behavioral responses in rats. Life Sci 43:1207-1213

Lewis DA, Anderson SA (1995): The functional architecture of the prefrontal cortex and schizophrenia [editorial] Psychol Med 25:887-894

Lewis SW, Murray RM (1987): Obstetrical complications, neurodevelopmental deviance, and risk of schizophrenia. J Psychiatr Res 21:413-421

Lieberman JA, Alvir J, Geisler S, Ramos-Lorenzi J, Woerner M, Novacenko H, Cooper T, Kane JM (1994a): Methylphenidate response, psychopathology and tardive dyskinesia as predictors of relapse in schizophrenia. Neuropsychopharmacology 11(2):107-118

Lieberman JA, Bogerts B, Degreef G, Ashtari M, Alvir J (1992): Qualitative assessment of brain morphology in acute and chronic schizophrenia. Am J Psychiatry 149(6):784-794

Lieberman JA, Kinon BJ, Loebel AD (1990): Dopaminergic mechanisms in idiopathic and drug-induced psychoses. Schizophr Bull 16(1):97-109

Lieberman JA, Jody D, Alvir J, Ashtari M, Levy D, Bogerts B, Degreef G, Mayerhoff D, Cooper T (1993a): Brain morphology, dopamine, and eye-tracking abnormalities in first-episode schizophrenia. Arch Gen Psychiatry 50: 357-368

Lieberman JA, Jody D, Geisler S, Alvir J, Loebel A, Szymanski S, Woerner M, Borenstein M (1993b): Time course and biological correlates of treatment response in firstepisode schizophrenia. Arch Gen Psychiatry 50:369-376

Lieberman JA, Kane JM, Alvir JAJ (1987): Provocative tests with psychostimulant drugs in schizophrenia. Psychopharmacology 91:415-433

Lieberman JA, Koreen AR (1993): Neurochemistry and neuroendocrinology of schizophrenia: a selective review. Schizophr Bull 19(2):371-429

Lieberman I, Koreen A, Loebel A, Geisler S, Alvir J, Volkow $\mathrm{N}$ (1994b): Evidence for sensitization in the early stage of schizophrenia. Presented at the XIXth Collegium Internationale Neuro-Psychopharmacologicum Congress, Washington, DC, June 27-July 1
Lieberman J, Alvir JM, Koreen A, Geisler S, Chakos M, Sheitman B, Woerner M (1996): Psychobiologic correlates of treatment response in schizophrenia. Neuropsychopharmacology 14(3S):13S-21S

Lipska BK, Jaskiw GE, Braun AR, Weinberger DR (1995): Prefontal cortical and hippocampal modulation of haloperidol-induced catalepsy and apomorphine-induced stereotypic behaviors in the rat. Biolog Psychiatry 38(4): 255-262

Lipska BK, Jaskiw GE, Chrapusta S, Karoum F, Weinberger DR (1992): Ibotenic acid lesion of the ventral hippocampus differentially affects dopamine and its metabolites in the nucleus accumbens and prefrontal cortex in the rat. Brain Res 585:1-6

Lipska BK, Weinberger DR (1993a): Postpubertal emergence of hyperresponsiveness to stress and to amphetamine after neonatal excitotoxic hippocampal damage: A potential animal model of schizophrenia: Neuropsychopharmacology 9(1):67-75

Lipska BK, Weinberger DR (1993b): Cortical regulation of the mesolimbic dopamine system: implications for schizophrenia. In Kalivas PW, Barnes CD (eds), Limbic Motor Circuits and Neuropsychiatry. Boca Raton, CRC Press, pp 329-349

Loebel AD, Lieberman JA, Alvir JMJ, Mayerhoff DI, Geisler SH, Szymanski SR (1992): Duration of psychosis and outcome in first-episode schizophrenia. Am J Psychiatry 149(9):1183-1188

Loebel AD, Lieberman JA, Alvir J, Geisler S, Koreen A, Chakos M (1995): Time to treatment response in successive episodes of early onset schizophrenia. Presented at the International Congress on Schizophrenia Research in Hot Springs, Virginia, April 8-12, 1995

Logan J, Dewey SL, Wolf AP, Fowler JS, Brodie JD, Angrist B, Volkow ND, Gatley SJ (1991): Effects of endogenous dopamine on measures of $[18 \mathrm{~F}] \mathrm{N}$-methylspiroperidol binding in the basal ganglia: comparison of simulations and experimental results from PET studies in baboons. Synapse 9(3):195-207

Mari JJ, Steiner DL (1994): An overview of family interventions and relapse on schizophrenia: meta-analysis of research findings. Psychol Med 34(3):565-578

Marshall BE, Longnecker DE (1990): General anesthetics. In Gilman AG, Rall TW, Nies AS, Tayler P (eds), Goodman and Gilman's The Pharmacological Basis of Therapeutics, 8th ed. New York, Pergamon Press, pp 285-309

Martin-Iverson MT, Reimer AR (1994): Effects of nimodopine and /or haloperidol on the expression of conditioned locomotion and sensitization to cocaine in rats. Psychopharmacology 114(2):315-320

May PR, Tuma AH, Dixon WJ (1981): Schizophrenia: a followup study of the results of five forms of treatment. Arch Gen Psychiatry 38:776-784

McCarley RW, Faux SF, Shenton ME, Nestor FG, Adams J (1991): Event-related potentials in schizophrenia: their biological and clinical correlates and a new model of schizophrenic pathophysiology [Review] [110 refs]. Schizophr Res 4(2):209-231

McCarley RW, Shenton ME, O'Donnell BF, Faux SF, Kikinis R, Nestor PG, Jolesz FA (1993): Auditory P300 abnormalities and left posterior superior temporal gyrus vol- 
ume reduction in schizophrenia. Arch Gen Psychiatry 50(3):190-197

McCreadie RG, Williamson DJ, Athawes RW, Connolly MA, Tilak-Singh D (1993): The Nithsdale schizophrenia surveys. XIII. Parental rearing patterns, current symptomatology and relatives expressed emotion. Br J Psychiatry 165(3):347-352

McDougle CJ, Black JE, Malison RT, Zimmermann RC, Kosten TR, Heninger GR, Price LH (1994): Noradrenergic dysregulation during discontinuation of cocaine use in addicts. Arch Gen Psychiatry 51(9):713-719

McGlashan TH, Fenton WS (1993): Subtype progression and pathophysiologic deterioration in early schizophrenia. Schizophr Bull 19(1):71-84

McNamara JO, Yeh G, Bonhaus DW, Okazaki M, Nadler JV (1990): NMDA receptor plasticity in the kindling model. In Ben-Ari Y (ed), Excitatory Amino Acids and Neuronal Plasticity. New York, Plenum Press

Mednick SA, Hollister JM (1995): Neural Development in Schizophrenia: Theory and Research. New York, Plenum Press

Meltzer HY, Stahl SM (1976): The dopamine hypothesis of schizophrenia: A review. Schizophr Bull 2:19-76

Mody I (1993): The molecular basis of kindling. Brain Pathology 3:395-403

Morgenson GJ, Brudzynski SM, Wu M, Yang CR, Yim CCY (1993): From motivation to action: a review of dopaminergic regulation of limbic, nucleus accumbens, ventral pallidum, pedunculopontine nucleus circuities involved in limbic-motor integration. In Kalivas PW, Barnes D (eds), Limbic Motor Circuits and Neuropsychiatry. Boca Raton, CRC Press, pp 193-236

Murray AM, Hyde TM, Knable MB, Herman MM, Bigelow LB, Carter JM, Weinberger DR, Kleinman JE (1995): Distribution of putative D4 dopamine receptors in postmortem striatum from patients with schizophrenia. J Neurosci 15(3):2186-2191

Murray RM, Reveley AM, McGuffin P (1986): Genetic vulnerability to schizophrenia. Psychiatr Clin North Am 9(1):3-16

Murray RM, O'Callaghan E, Castle DJ, Lewis SW (1992): A neurodevelopmental approach to the classification of schizophrenia. Schizophr Bull 18(2):319-332

Murray RM (1994): Neurodevelopmental schizophrenia: The rediscovery of dementia praecox. Br J Psychiatry (Suppl)25:6-12

Neppe VM (1985): Epilepsy and psychiatry: essential links. Psychiatric Insights 2(2):18-22.

Nestler EJ, Hope BT, Widnell KL (1993): Drug addiction: A model for the molecular basis of neural plasticity. Neuron 11:995-1006

Normon AB, Lu SY, Klug JM, Norgren RB (1993): Sensitization of cFOS expression in rat striatum following multiple challenges with D-amphetamine. Brain Res 603(1): 125-128

Norman RM, Malla AK (1993): Stressful life events and schizophrenia. I: A review of the research. Br J Psychiatry 162:161-166

O'Donnell P, Grace AA (1995): Synaptic interactions among excitatory afferents to nucleus accumbens neurons: Hip- pocampal gating of prefrontal cortical input. J Neurosci 15(5 pt 1):3622-3639

Olney JW (1989): Excitatory amino acids and neuropsychiatric disorders. Biolog Psychiatry 26:505-525

Olney JW, Farber NB (1995): Glutamate receptor dysfunction and schizophrenia. Arch Gen Psychiatry 52:998-1007

Olney JW, Zorunski CF, Stewart GR, Price MT, Want GJ, Labruyere J (1990): Excitotoxicity of L-dopa and 6-OHdopa: Implications for Parkinson's and Huntington's diseases. Experimental Neurol 108(3):269-272

Orner RJ (1992): Post-traumatic stress disorders in European war veterans. Br J Clin Psychol 31:387-403

Orr SP (1990): Psychophysiologic studies of post-traumatic stress disorders. In Giller EL (ed), Biological Assessment and Treatment of Post Traumatic Stress Disorder. Washington, DC, American Psychiatric Press

Pearce RK, Seeman P, Jellinger K, Tourtellotte WW (1990): Dopamine uptake sites and dopamine receptors in Parkinson's disease and schizophrenia. European J Neurol 30(Suppl 1):9-14

Pert A, Post R, Weiss SRB (1992): Conditioning as a critical determinant of sensitization induced by psychomotor stimulants. In Erinoff L (ed), Neurobiology of Drug Abuse: Learning and Memory. Washington, DC, NIDA, p 208

Pilowsky LS, Costa DC, Ell PJ, Murray RM, Verhoeff NP, Kerwin RW (1993): Antipsychotic medication, D2 dopamine receptor blockade and clinical response: a 123I IBZM SPET (single photon emission tomography) study. Psychol Med 23(3):791-797

Post RM, Weiss SRB (1992a): Endogenous biochemical abnormalities in affective illness: therapeutic versus pathogenic. Biol Psychiatry 32:469-484

Post RM (1992b): Transduction of psychosocial stress into the neurobiology of recurrent affective disorder. Am J Psychiatry 149:999-1010

Post RM, Rubinow DR, Ballenger JC (1986): Conditioning and sensitization in the longitudinal course of affective illness. Br J Psychiatry 149:191-201

Post RM (1980): Intermittent versus continuous stimulation: Effect of time interval on the development of sensitization or tolerance. Life Sciences 26:1275-1282

Post RM, Kopanda RT (1976): Cocaine, kindling, and psychosis. Am J Psychiatry 133(6):627-634

Post RM, Weiss SR, Pert A (1988): Implication of behavioral sensitization and kindling for stress-induced behavioral change. Adv Exp Med Biol 245:441-463

Pycock CJ, Carter CJ, Kerwin RW (1980): Effect of 6-hydroxydopamine lesions of the medial prefrontal cortex on neurotransmitter systems in subcortical sites in the rat. J Neurochemistry 34(1):91-99

Rada P, Hernandez L (1990): Opposite changes of dopamine turnover in prefrontal cortex and nucleus accumbens after amygdaloid kindling. Neurosci Lett 117:144-148

Randrup A, Munkvad I (1965): Special antagonism of amphetamine-induced abnormal behaviour. Inhibition of stereotyped activity with increase of some normal activities. Psychopharmacologia 7(6):416-422

Regier DA, Myers JK, Kramer M, Robins LN, Blazer DG, 
Hough RL, Eaton WW, Locke BZ (1984): The NIMH Epidemiologic Catchment Area program. Historical context, major objectives, and study population characteristics. Arch Gen Psychiatry 41(10):934-941

Reith MEA, Benuch M, Lajtha A (1987): Cocaine disposition in the brain after continuous or intermittent treatment of locomotor stimulation in mice. J Pharmacol Experim Therap 243:281-287

Robertson HA (1992): Immediate-early genes, neuronal plasticity, and memory. Biochem Cell Biol 70:729-737

Robinson TE, Becker JB, Moore CJ, Castaneda E, Mittleman G (1985): Enduring enhancement in frontal cortex dopamine utilization in an animal model of amphetamine psychosis. Brain Res 343(2):374-377

Robinson TE, Becker JB (1986): Enduring changes in brain and behavior produced by chronic amphetamine administration: A review and evaluation of animal models of amphetamine psychosis. Brain Res Rev 11: 157-198

Robinson TE, Berridge KC (1993): The neural basis of drug craving: an incentive-sensitization theory of addiction. Brain Res Rev 18(3):247-291

Rosen JB, Davis M (1988): Enhancement of acoustic startle by electrical stimulation of the amygdala. Behav Neurosci 102(2):195-202

Roth RH, Tam SY, Ida Y, Yang JX, Deutch AY (1988): Stress and the mesocorticolimbic dopamine system. Ann NY Acad Sci 537:138-147

Sato K, Morimoto K, Okamoto M (1988): Anticonvulsant action of a non-competitive antagonist of NMDA receptors (MK-801) in the kindling model of epilepsy. Brain Res 463:12-20

Sato M, Numachi Y, Hamamura T (1992): Relapse of paranoid psychotic state in methamphetamine model of schizophrenia. Schizophr Bull 18:115-122

Scalzo FM, Holson RR (1992): The ontogeny of behavioral sensitization to phencyclidine. Neurotoxical Teratol 14(1):7-14

Schenk S, Snow S (1994): Sensitization to cocaine's motor activating properties produced by electrical kindling of the medial prefrontal cortex but not of the hippocampus. Brain Res 659(1-2):17-22

Schultz W, Romo R (1990): Dopamine neurons of the monkey midbrain: contingencies of responses to stimuli eliciting immediate behavioral reactions. J Neurophysiol 63:607-624

Sedvall G (1992): The current status of PET scanning with respect to schizophrenia. Neuropsychopharmacology $8(1): 41-54$

Seeger TF, Thal L, Gardner EL (1982): Behavioral and biochemical aspects of neuroleptic-induced dopaminergic supersensitivity: Studies with chronic clozapine and haloperidol. Psychopharmacology 76:182-187

Seeman P, Lee T, Chau-Wong M, Wong K (1976): Antipsychotic drug doses and neuroleptic/dopamine receptors. Nature 261:717-719

Seeman P (1987): Dopamine receptors and the dopamine hypothesis of schizophrenia. Synapse 1(2):133-152

Seeman P, Bzowej NH, Guan HC, Bergeron C, Reynolds GP, Bird ED, Riederer P, Jellinger $K$, Tourtellotte WW
(1987): Human brain D1 and D2 dopamine receptors in schizophrenia, Alzheimer's, Parkinson's, and Huntington's diseases. Neuropsychopharmacology 1(1):5-15

Seeman P, Van Tol HHM (1994): Dopamine receptor pharmacology. Trends Pharmacol Sci 15:264-270

Seeman P, Sunahara RK, Niznik HB (1994): Receptor-receptor link in membranes revealed by ligand competition: example for dopamine D1 and D2 receptors. Synapse 17:62-64

Seeman P, Van Tol HH (1995): Dopamine D4-like receptor elevation in schizophrenia: cloned D2 and D4 receptors cannot be discriminated by raclopride capetition agonist [31-1] nemonapride. J Neurochem 64(3):1413-1415

Segal DS, Kuczenski R (1992): In vivo microdialysis reveals a diminished amphetamine-induced DA response corresponding to behavorial sensitization produced by repeated amphetamine pretreatment. Brain Res 571: 330-337

Seiden LS, Vosmer G (1984): Formation of 6-hydroxydopamine in caudate nucleus of the rat brain after a single large dose of methylamphetamine. Pharmacol Biochem Behavior 21:29-31

Selzer JA, Lieberman JA (1993): Schizophrenia and substance abuse. Psychiatr Clin North Am 16(2):401-412

Shaw CA, Lanius RA, van den Doel K (1994): The origin of synaptic neuroplasticity: crucial molecules or a dynamical cascade? Brain Res Rev 19:241-263

Shenton ME, Kikinis R, Jolesz FA, Pollak SD, LeMay M, Wible CG, Hokama H, Martin J, Metcalf D, Coleman M et al (1992): Abnormalities of the left temporal lobe and thought disorder in schizophrenia. A quantitative magnetic imaging study. N Engl J Med 327(9):604-612

Snyder SH (1987): Psychotogenic drugs as models for schizophrenia. Comments on "the current status of the dopamine hypothesis of schizophrenia". Neuropsychopharmacology 1(3):197-199

Snyder SH, Banerjee SP, Yamamura HI, Greenberg D (1974) Drugs, neurotransmitters, and schizophrenia. Science 184:1243-1253

Solomon Z (1989): Characteristic psychiatric symptomatology of post-traumatic stress disorder in veterans: a three year follow up. Psychol Med 9:927-936

Solomon Z, Mikulincer M, Jakob BR (1987): Exposure to recurrent combat stress: Combat stress reactions among Israeli soldiers in the Lebanon War. Psychol Med 17: 433-440

Sorg BA, Kalivas PW (1993): Effects of cocaine and footshock stress on extracellular dopamine levels in the medial prefrontal cortex. Neuroscience 53:695-703

Sorg BA, Kalivas PW (1991): Effects of cocaine and footshock stress on extracellular dopamine levels in the ventral striatum. Brain Res 559:29-36

Southwick SM, Bremmer D, Crystal JH, Charney DS (1994): Psychobiological research in post-traumatic stress disorder. Psychiatr Clin North Am 17(2):251-264

Stevens JR (1988): Psychiatric aspects of epilepsy. J Clin Psychiatry Suppl 49:49-57

Stewart J, Vezina P (1989): Microinjections of SCH-23990 into the ventral tegmental area and substantia nigra pars reticulata attenuate the development of sensitization to 
the locomotor activating effects of systemic amphetamine. Brain Res 495:401-406

Suddath RL, Christison GW, Torrey EF, Casanova MF, Weinberger DR (1990): Anatomical abnormalities in the brains of monozygotic twins discordant for schizophrenia [published erratum appears in N Engl J Med 1990 May 31;322(22):1616] [see comments]. N Engl J Med 322(12):789-794

Susser ES, Lin EP (1992): Schizophrenia after prenatal exposure to the Dutch hunger winter of 1944-1945. Arch Gen Psychiatry 49(12):983-988

Sutula TP (1990): Experimental models of temporal lobe epilepsy: New insights from the study of kindling and synaptic reorganization. Epilepsia 31(Suppl 3):S45-S54

Sweatt JD, Kandel ER (1989): Persistent and transcriptionally-dependant increase in protein phosphorylation in long term facilitation of Aplasia sensory neurons. Nature 339:52-54

Takahashi LK, Turner JG, Kalin NH (1992): Prenatal stress alters brain catecholaminergic activity and potentiates stress-induced behavior in adult rats. Brain Res 574(12):131-137

Tarazi FI, Florign WJ, Creese I (1994): Regulation of dopamine receptor binding following chronic neuroleptic treatment. Society for Neuroscience Abstracts Nov. 1994, p 1772

Teyler TJ, DiScenna P (1987): Long-term potentiation. Ann Rev Neurosci 10:131-161

Tomb DA (1994): The phenomenology of post-traumatic stress disorder. Psychiatr Clin North Am 17(2):237-250

Torrey EF (1991): A viral-anatomical explanation of schizophrenia. Schizophr Bull 17(1):15-18

Tsai G, Passani LA, Slusher BS, Carter R, Baer L, Kleinman JE, Coyle JT (1995): Abnormal excitatory neurotransmitter metabolism in schizophrenic brains. Arch Gen Psychiatry 52(1):829-836

Tsuang MT, Lyons MJ, Faraone SV (1990): Heterogeneity of schizophrenia: Conceptual models and analytic strategies. Br J Psychiatry. 156:17-26

Tsuang MT, Gilbertson MW, Faroane SV (1991): The genetics of schizophrenia. Current knowledge and future directions. Schizophr Res 4:157-171

Tsuchida K, Ujike H, Kanzaki A, Fujiwara Y, Akiyama K (1994): Ontogeny of enhanced striatal dopamine release in rats with methamphetamine-induced behavioral sensitization. Pharmacol Biochem Behav 47:161-169

Ujike H, Onoue T, Akiyama K, Hamamura T, Otsuki S (1989): Effects of selective D-1 and D-2 dopamine antagonists on development of methamphetamine-induced behavioral sensitization. Psychopharmacology 98(1):89-92

Ujike H, Akiyama K, Otsuki S (1990): D-2 but not D-1 dopamine agonists produce augmented behavioral response in rats after subchronic treatment with methamphetamine or cocaine. Psychopharmacology 102: $459-464$

Umbricht D, Degreef G, Barr WB, Lieberman JA, Pollack S, Schaul N (1995): Postictal and chronic psychoses in patients with temporal lobe epilepsy. Am J Psychiatry 152(2):224-231

Van Kammen DP, Docherty JP, Marder SR, Royner JN, Bun- ney WE Jr (1982): Long-term pimozide pretreatment diffentially affects behavioral responses to dextroamphetamine in schizophrenia. Further exploration of the dopamine hypothesis of schizophrenia. Arch Gen Psychiatry 39(3):275-281

Vezina P, Stewart J (1989): The effect of dopamine receptor blockade on the development of sensitization to the locomotor activating effects of amphetamine and morphine. Brain Res 499:108-120

Volkow ND, Fowler JS, Wang GJ, Hitzemann R, Logan J, Schlyer DJ, Dewey SL, Wolf AP (1993): Decreased dopamine D2 receptor availability is associated with reduced frontal metabolism in cocaine abusers. Synapse 14(2):169-177

Volkow ND, Wang GJ, Fowler JS, Logan J, Schlyer D, Hitzemann R, Lieberman J, Angrist B, Pappas N, MacGregor R, Burr G, Cooper T, Wolf AP (1994): Imaging endogenous dopamine competition with [11C]raclopride in the human brain. Synapse 16(4):255-262

Volkow ND, Ding YS, Fowler C, Wang G-J, Logan J, Gatley JS, Dewey S, Ashby C, Lieberman J, Hitzemann R, Wolf AP (1995): Is methylphenidate like cocaine? Studies on their pharmacokinetics and distribution in the human brain. Arch Gen Psychiatry 52(6):456-463

Von Voightlander PF, Moore KE (1971): Involvement of nigrostriatal neurons in the in-vivo release of dopamine by amphetamine, amantadine, and tyramine. J Pharmacol Exp Ther 184:542-552

Waddington JL, O'Callaghan EO, Youssef HA, Buckley P, Lane A, Cotter D, Larkin C (In press): Schizophrenia as a 'cascade' process and the evidence for its neurodevelopmental original. In Susser E and Gorman L (eds), Epigenetic Causes of Schizophrenia. Washington, DC, American Psychiatric Press

Walker E, Downey G, Caspi A (1991): Twin studies of psychopathology: why do the concordance rates vary? Schizophr Res 5(3):211-221

Walker E, Lewine RJ (1990): Prediction of adult-onset schizophrenia from childhood home movies of the patients. Am J Psychiatry 147(8):1052-1056

Watt NF (1978): Patterns of childhood social development in adult schizophrenics. Arch Gen Psychiatry 35:160-165

Wedzony K, Golembiwska K, Klimek V (1993): MK-801 induced symptoms of sensitization. The lack of correlation with the extracellular concentration of dopamine in the rat prefrontal cortex. Brain Res 625(2):333-336

Weinberger DR (1995): Models of schizophrenia. 5th International Congress on Schizophrenia Research. Hot Springs, Virginia, April, 1995

Weinberger DR, Berman KF, Illowsky BP (1988): Physiologic dysfunction of the prefrontal cortex in schizophrenia: III. A new cohort and evidence of a monoaminergic mechanism. Arch Gen Psychiatry 45:609-615

Weinberger DR (1987): Implications of normal brain development for the pathogenesis of schizophrenia. Arch Gen Psychiatry 44:660-669

Weinberger DR (1984): Computed tomography (CT) findings in schizophrenia: speculation on the meaning of it all. J Psychiatr Res 18(4):477-490

Weiss SR, Post RM, Pert A, Woodward R, Murman D (1989): Context-dependent cocaine sensitization: differential 
effect of haloperidol on development versus expression. Pharmacol Biochem Behavior 34(3):655-661

Wilson JM, Pristupa ZB, Niznik HB, Kish SJ (1993): [ $\left.{ }^{3} \mathrm{H}\right]$ WIN 35,428 Binding in human caudate: pharmacological profile. Presented at the 23rd Annual Meeting of the Society for Neuroscience, Washington, DC

Wolf ME, White FJ, Nassar R, Brooderson RJ, Khansa MR (1993): Differential development of autoreceptor subsensitivity and enhanced dopamine release during amphetamine sensitization. J Pharmacol Exp Ther 264(1):249-255

Wolf ME, Khansa MR (1991): Repeated administration of MK-801 produces sensitization to its own locomotor stimulant effects but blocks sensitization to amphetamine. Brain Res 562(1):164-168

Wolkin A, Barouche F, Wolf AP, Rotrosen J, Fowler JS, Shiue CY, Cooper TB, Brodie JD (1989): Dopamine blockade and clinical response: evidence for two biological subgroups of schizophrenia. Am J Psychiatry 146(7): 905908
Wong DF, Wagner HN, Tune LE, Dannals RF, Pearlson GD, Links JM, Tamminga CA, Broussole EP, Ravert HT, Wilson AA, Toung JK, Malat J, Williams JA, O'Tuama LA, Snyder SH, Kuhar MJ, Gjedde A (1986): Positron emission tomography reveals elevated D2 dopamine receptors in drug naive schizophrenics. Science 234:1558-1563

Wyatt RI (1991): Neuroleptics and the natural course of schizophrenia. Schizophr Bull 17(2):325-351

Wyatt RJ (1995): Early intervention for schizophrenia: Can the course of the illness be altered. Biol Psychiatry 38:1-3

Yoshikawa T, Shibuya H, Kaneno S, Toru M (1991): Blockade of behavioral sensitization to methamphetamine by lesion of hippocampal-accumbal pathway. Life Sci 48:1325-1332

Zigmond MJ, Abercrombie ED, Berger TW, Grace AA, Stricker EM (1990): Compensations after lesions of central dopaminergic neurons: some clinical and basic implications. Trends Neurosci 13(7):290-296

Zubin J, Spring B (1977): Vulnerability-a new view of schizophrenia. J Abn Psychology 86(2):103-126 